\title{
A Summary Review of Correlations between Temperatures and Vibration Properties of Long-Span Bridges
}

\author{
Guang-Dong $\mathrm{Zhou}^{1}$ and Ting-Hua $\mathrm{Yi}^{2,3}$ \\ ${ }^{1}$ College of Civil and Transportation Engineering, Hohai University, Nanjing 210098, China \\ ${ }^{2}$ School of Civil Engineering, Dalian University of Technology, Dalian 116023, China \\ ${ }^{3}$ State Key Laboratory for Disaster Reduction in Civil Engineering, Tongji University, Shanghai 200092, China \\ Correspondence should be addressed to Guang-Dong Zhou; zhougd@hhu.edu.cn
}

Received 8 January 2014; Accepted 6 March 2014; Published 13 April 2014

Academic Editor: Hua-Peng Chen

Copyright (C) 2014 G.-D. Zhou and T.-H. Yi. This is an open access article distributed under the Creative Commons Attribution License, which permits unrestricted use, distribution, and reproduction in any medium, provided the original work is properly cited.

\begin{abstract}
The shift of modal parameters induced by temperature fluctuation may mask the changes of vibration properties caused by structural damage and result in false structural condition identification. Thoroughly understanding the temperature effects on vibration properties of long-span bridges becomes an especially important issue before vibration-based damage detection methodologies are applied in real bridges. This paper presents an overview of current research activities and developments in the field of correlations between temperatures and vibration properties of long-span bridges. The theoretical derivation methods using classical structural dynamics and closed-form formulations are first briefly introduced. Then the trend analysis methods that are intended to extract the degree of variability in vibration property under temperature variation for different bridges by numerical analysis, laboratory test, or field monitoring are reviewed in detail. Following that, the development of quantitative models to quantify the temperature influence on vibration properties is discussed including the linear model, nonlinear model, and learning model. Finally, some promising research efforts for promoting the study of correlations between temperatures and vibration properties of long-span bridges are suggested.
\end{abstract}

\section{Introduction}

The long-span bridges which represent the key elements in terms of the safety and functionality of the entire transportation system are susceptible to the combined action of environmental conditions (e.g., temperature, winds, rains, and humidity), service loads (e.g., railway loads, highway loads), and catastrophic events (e.g., earthquakes, hurricanes, floods, and vehicle collision) [1-3]. In the United States, 15\% of 595,000 bridges were rated as being deficient for structural reasons by the US Federal Highway Agency (FHWA) in 2005 and more than 134 bridges were reported to have partially or totally collapsed between 1989 and 2000 [46]. Therefore, how to maintain structural safety becomes a challenging task. Structural health monitoring (SHM), which aims at monitoring structural behavior in real-time, evaluating structural performance under various loads, and identifying structural damage or deterioration, provides a better solution for this problem [7-10]. Recent advances in sensing, data acquisition, computing, communication, and data and information management have greatly promoted the applications of SHM technology in bridge structures [11]. At present, SHM has been extensively implemented on existing or newly built bridges in Europe, USA, Canada, Japan, Korea, China, and other countries $[12,13]$.

For a sophisticated bridge SHM system, one of the extremely important functions is damage detection, which is also the original intention of developing SHM technology. In order to fulfill this requirement, a variety of damage detection methods have been proposed for different types of long-span bridges. Among them, the vibration-based methodology is dominant [14-16]. The basic concept underlying the use of vibration-based damage detection is that global vibration properties, notably natural frequencies, mode shapes, and modal damping, are functions of the physical parameters 
of the structural mass, damping, and stiffness. Changes in the physical parameters will cause detectable changes in the vibration properties [17]. Up to now, various damage detection methods that are based on the vibration properties or their derivatives have been developed, such as coordinate modal assurance criterion (COMAC), enhanced coordinate modal assurance criterion (ECOMAC), damage index (DI) method, mode shape curvature (MSC) method, modal flexibility index (MFI), changes in stiffness matrix obtained from measured mode shapes, and changes in the curvature of uniform load surface [18-21]. However, the application of vibration-based damage detection methods for real longspan bridges is complicated, because vibration properties of a real structure are strongly affected by factors other than structural damages [22]. Environmental changes, especially temperature, also cause changes in vibration properties, such as frequency, mode shapes, and damping ratio, which may mask the changes caused by structural damage [23]. To avoid false condition assessments, the variability of the vibration properties due to temperature must be thoroughly understood and quantified so that it can be discriminated from changes caused by damage [17]. As a matter of fact, the variation of temperatures affects vibration properties of longspan bridges in a complicated manner. Firstly, the temperature distribution and its variation in a bridge are generally nonuniform and time dependent, which induces that the changes of physical parameters among different structural parts are asynchronous [24]. Secondly, all members of a bridge change their size under different temperatures for the effect of thermal expansion and contraction [25]. Thirdly, the Young's modulus and the shear modulus of material, which are the main parameters determining vibration properties of bridges, vary because of the fluctuation of temperature. Fourthly, daily or seasonal variations in temperature may change the stiffness of bridge expansion joints or supports and thus strengthen or weaken the constraints, resulting in an apparent shift of vibration properties [26]. Lastly, temperature variations result in considerable thermal stresses or stress redistribution in structure, which may change the vibration properties of bridges. Numerous investigations indicate that temperature is the critical source causing the variability of vibration properties of long-span bridges, and the variations of modal frequencies caused by temperature may reach $5 \%$ to $10 \%$ for highway bridges, which in most cases exceed the changes of frequencies due to structural damage or deterioration [12].

During the past decades, considerable effort has been devoted to investigating the correlations between temperatures and vibration properties of long-span bridges. According to the approach of researching, the existing achievements can be categorized into three types, termed as theoretical derivation, trend analysis, and quantitative model. The theoretical derivation is used to establish closed-form formulations of the correlations between temperatures and vibration properties of long-span bridges by classical structural dynamic methods. The trend analysis is applied to analyze the variation of vibration properties of long-span bridges caused by temperature changes through numerical simulation, laboratory test, and field monitoring. The quantitative model is intended to develop no physical blind models, which can quantificationally forecast changes in vibration properties based on the input of time series of new temperatures through a large amount of measurement data. This paper aims to present a summary review of correlations between temperatures and vibration properties of long-span bridges. Although Xia et al. [30] gave a literature review concerning variations in vibration properties of civil structures under changing temperature conditions before, the content is too sketchy to give reference for later research. Furthermore, some important contributions were omitted. In the following sections, research progress of correlations between temperatures and vibration properties of long-span bridges is extensively described from theoretical derivation method, trend analysis approach, and quantitative model. In addition, some existing problems and promising research efforts about this topic are expected to be extracted through pertinent assessment. This paper is not intended to list all the literature about the effects of temperature on vibration properties of bridges but exhibit some representative achievements, which are expected to provide reference for future research.

\section{Progress of Theoretical Derivation Method}

A long-span bridge is a complex multi-degree-of-freedom nonlinear system. This makes it is extremely difficult to formulate the vibration properties by closed-form equations. Furthermore, temperature change affects a bridge in a complicated way. It not only affects mechanical properties, but also geometrical features, constraint conditions, and boundary conditions. As a result, only a few researchers have investigated the correlations between temperatures and vibration properties of long-span bridges through the theoretical derivation methods.

In order to simplify the problem, Xia et al. [34] assumed that mass and the boundary conditions remain unchanged, and temperature affects only the geometry and mechanical properties. A single-span beam made of an isotropic material was used as an example to model the effect of temperature on natural frequencies. For this beam, its undamped flexural vibration frequency of order $n$ is [35]

$$
f_{n}=\frac{n^{2} \pi h}{2 l^{2}} \sqrt{\frac{E}{12 \rho}},
$$

where $f_{n}$ denotes the $n$th frequency, $h$ and $l$ are the height and length of the beam, respectively, $E$ represents the modulus of elasticity, and $\rho$ denotes the density of the material. The variation of the above equation can be expressed as

$$
\frac{\delta f_{n}}{f_{n}}=\frac{\delta h}{h}-2 \frac{\delta l}{l}+\frac{1}{2} \frac{\delta E}{E}-\frac{1}{2} \frac{\delta \rho}{\rho},
$$


where $\delta$ represents an increment in the corresponding parameter. Assuming the thermal coefficient of linear expansion of the material is $\theta_{t}$ and the temperature coefficient of modulus is $\theta_{E}$, one obtains

$$
\begin{gathered}
\frac{\delta h}{h}=\theta_{t} \delta t, \quad \frac{\delta l}{l}=\theta_{t} \delta t, \quad \frac{\delta \rho}{\rho}=-3 \theta_{t} \delta t, \\
\frac{\delta E}{E}=\theta_{E} \delta t,
\end{gathered}
$$

where $t$ is the temperature of the beam. Here it is assumed that the Young's modulus variation with temperature is linear for small temperature changes. Consequently (2) yields

$$
\frac{\delta f_{n}}{f_{n}}=\frac{1}{2}\left(\theta_{t}+\theta_{E}\right) \delta t .
$$

For prismatic multispan beams, the natural frequencies can be expressed in a similar form to those of a simply supported beam as $[30,34]$

$$
f_{n}=\frac{\lambda_{n}^{2} \pi h}{2 l^{2}} \sqrt{\frac{E}{12 \rho}}
$$

where $\lambda_{n}$ is a dimensionless parameter and is a function of the boundary conditions. Consequently, (2)-(4) are still applicable for multispan beam structures.

The thermal axial force that arises because of changes in the support bearings alters the natural frequencies by changing the longitudinal bending stiffness. The frequencies of the beam under constant axial force are, based on the analysis of Clough and Penzien [35],

$$
f_{n}^{\prime}=f_{n} \sqrt{1+\frac{F l^{2}}{n^{2} \pi^{2} E I}}
$$

where $f_{n}^{\prime}$ denotes the modal frequency including axial force, $F$ represents the constant axial force, and $I$ is the moment of inertia.

Equation (4) estimates the dimensionless rate of the frequency variation with the temperature change. For steel or concrete, $\theta_{E}$ is obviously much larger than $\theta_{t}$, which indicates that variations in natural frequency subjected to temperature change are controlled by $\theta_{E}$. It also shows that the variation percentage of natural frequency is a function of the modulus thermal coefficients only, regardless of modes, spans, and beam types (simply supported, multispan, or cantilever beam).

\section{Developments of Trend Analysis Approach}

For a real bridge, it is impossible to describe its vibration properties by theoretical formulations exactly except by introducing many rigorous hypotheses. Trend analysis, which intends to assess the trend and degree that the vibration properties of long-span bridges change with the fluctuation of temperature, becomes an indispensable alternative. Three approaches can be used to conduct the trend analysis: the numerical simulation approach, the laboratory test approach, and the field monitoring approach. The SHM system obtains long-term bridge vibration data and corresponding temperatures of the structure, which provides a wonderful opportunity to extracting the correlations between temperatures and vibration properties of long-span bridges.

3.1. Numerical Simulation Approach. Fu and DeWolf [36] developed a nonlinear dynamic finite element (FE) analysis to assess the changes of frequencies in a two-span skewed composite bridge due to the partially restrained bearings. The FE model was based on use of beam elements for the girders and diaphragms and shell elements for the slab. The field data in the unrestrained state was used to calibrate the FE model to account for the nonlinear cracking behavior in the slab and diaphragm interaction. The FE model was then modified to account for changes in the vibrational behavior due to the eccentrically applied bearing forces, which occurred when the bearings were partially restrained in colder weather. With this analysis, it was confirmed that the variations of boundary conditions due to temperature fluctuation cause a change in the natural frequencies.

Macdonald and Daniell [37] established a detailed FE model for a cable-stayed bridge with a main span of $456 \mathrm{~m}$. The reinforced concrete (RC) slab of the deck was modeled with four shell elements and the longitudinal girder was modeled with beam elements. The transverse trusses and cable anchorage beams were represented by beam elements. The bearings were modeled as fixed in all translational directions, whilst being free to rotate. Modal analyses were performed on the FE model for two different temperature conditions. The first condition was a uniform temperature change of $5^{\circ} \mathrm{C}$ to the whole structure, and the second was a temperature differential of $+10^{\circ} \mathrm{C}$ for the top of the deck compared to the rest of the structure. It was found that, for both conditions, the natural frequencies of about one third of the modes shifted by up to $\pm 0.2 \%$, while there was no noticeable change in the others. This analysis indicated that the modal parameters of the bridge are not influenced significantly by normal temperature changes, which is a little bit different with the following outcomes.

$\mathrm{Xu}$ and $\mathrm{Wu}$ [38] implemented a systemic investigation about the frequency and mode shape curvature variations of a cable-stayed concrete box girder bridge caused by uniform temperature changes and nonuniform temperature changes through three-dimensional FE analysis. The FE model employs beam elements, link elements, contact elements, spring elements, and mass elements. Three factors including the size thermal effect induced by material thermal expansion coefficient, the change of elastic modulus of concrete, and the cables sag induced by cable gravity were considered. The results showed that the variation behavior of frequency and mode shape curvature caused by nonuniform temperature change is similar to those caused by uniform temperature change. The maximum variation ratio of frequency could be $2 \%$ as uniform temperature increases from -20 to $+40^{\circ} \mathrm{C}$. The effect of temperature on frequencies corresponding to bending mode type is more obvious, especially for the 
vertical bending mode. Changes of mode shape curvature due to ambient temperature variations usually happen at the midspan and one-fourth span of the central span, the midspan of the side span, and in supports in the cable-stayed bridge. The corresponding variation ratio is approximately $1-$ $8 \%$.

In order to outline the temperature effect, an FE model of bridge deck was developed by Balmès et al. [39]. The whole bridge span is modeled using 9600 standard 8node isoparametric volume elements and 13,668 nodes. The temperature variations were modeled using a uniform temperature elevation. It was found that the first frequency increases while the temperature decreases. Miao et al. [40] analyzed the dynamic characteristics of a three-tower and two-span suspension steel-box girder bridge at different global temperatures by spatial FE method. This bridge is the first multitower suspension bridge whose span exceeds $1000 \mathrm{~m}$ in the world. An equivalent cable force method was proposed to simulate temperature effects, and the effects of environmental temperature on dynamic characteristics of the bridge were studied. The result revealed that the effects of temperature cannot be neglected in dynamic analysis of suspension bridges. The relationship between temperature and frequency is negative.

As the temperature of an entire structure is generally nonuniformly distributed, using the air temperature or surface temperatures alone may not sufficiently capture the relation between the bridge vibration properties and temperatures. Xia et al. [28] proposed a new approach to investigate the variation of bridge vibration characteristics with respect to structural temperatures. In contrast to the conventional studies that use air temperature or temperatures at a few points of the structure, this study aims to obtain the thermal distribution of the entire structure from the thermodynamic models. As the material mechanical properties are temperature dependent, the structure was regarded as a composite structure consisting of elements with different Young's module. At first, an FE model was established to conduct a transient thermal analysis and estimate the temperature distribution of the slab. And then, the temperature data at all components and thermal properties of the material were inputted to the model to calculate the frequencies. Consequently, the relation between the frequencies and the temperature at the whole structure was established. A simply supported RC slab model was constructed and used as a proof-of-concept example. The outcomes of this study verified that the frequencies are global properties and are associated with the temperature distribution of the entire structure. Therefore, consideration of the temperature distribution of a whole structure will lead to more accurate results of the temperature effect on the vibration properties of the structure.

3.2. Laboratory Test Approach. When the numerical approach is adopted in trend analysis of the temperature effect on structural vibration properties, many hypotheses and simplifications must be employed and the outcomes depend on the input parameters. Therefore, the results obtained by the numerical approach may deviate from actual occasions. Contrarily, laboratory test can reveal the variations of structural vibration properties under different climates and provides more rational conclusions.

Xia et al. [34] carried out periodical vibration tests on a reinforced concrete slab for nearly two years. The slab, which measures $6400 \mathrm{~mm} \times 800 \mathrm{~mm} \times 100 \mathrm{~mm}$ with $3000 \mathrm{~mm}$ spans and $200 \mathrm{~mm}$ overhang on each end, was constructed and placed outside the laboratory exposed to weather conditions. Its vibration properties, namely, vibration frequencies, mode shapes, and damping, were measured together with the temperature during each measurement. It was found that the frequencies of first four modes have a strong negative correlation with temperature, damping ratios have a positive correlation, but no clear correlation of mode shapes with temperature change can be observed. The three bending modes gave similar results, namely, that the modal frequencies decrease $0.13 \%-0.23 \%$ when temperature increases by one degree, and the torsional mode that is affected by the shear rigidity of the structure has different sensitivity to temperature than bending rigidity does. The damping ratio increases slightly with the increase of temperature.

Kim et al. [27] performed a series of forced vibration tests on a model bridge for about 7 months from December 1999 to July 2000. The test model bridge is a single-span, stainless steel, plate girder bridge. The bridge spans $2.0 \mathrm{~m}$ and is simply supported with a set of pin supports at the left edge and a set of roller supports at the other edge. The superstructure of the bridge consists of the deck, the deck supporting systems, and piers. The substructure consists of four steel blocks and a system of steel frame bases. Environmental factors other than temperature were not considered during the tests. Experimental setups for locations and arrangements of accelerometers and excitation sources on the test structure were designed as shown in Figure 1. When these tests were performed, temperatures varied between a low of $-3^{\circ} \mathrm{C}$ and a high of $23^{\circ} \mathrm{C}$. The results demonstrated that, in all modes, natural frequencies go down as the temperature goes up. Bending modes are more sensitive than torsional modes. As one progresses to lower modes, the temperature has relatively greater effects on the change in natural frequency. Natural frequencies at 6 different temperatures are listed in Table 1. The first four frequencies decreased by about $0.64,0.33,0.44$, and $0.22 \%$, respectively, when temperature increased per unit degree. Two levels of damage were inflicted on a girder near the center of the structure: the bottom flange was cut halfway in from outside and the bottom flange was cut completely in from either side. The variations of vibration properties induced by damages are almost the same level as that caused by temperature changes.

Balmès et al. [41] carried out an aluminum beam experiment in a climatic chamber. The results demonstrated that the axial prestress of this beam because of thermal change varied significantly and led to changes in the first four frequencies by $16,8,5$, and $3 \%$, respectively. The variations in mode shapes were invisible when temperature decreased by about $17^{\circ} \mathrm{C}$. The effect of temperature on damping was also concerned, but no consistent conclusion was drawn. They stated that one possible reason is that the damping of structures is more 
TABLE 1: Predamage natural frequencies of model bridge at various temperatures (Kim et al. [27]).

\begin{tabular}{lcccccc}
\hline \multirow{2}{*}{$\begin{array}{l}\text { Mode } \\
\text { number }\end{array}$} & \multicolumn{6}{c}{ Frequency $(\mathrm{Hz})$ of undamaged structure at various } \\
& $0^{\circ} \mathrm{C}$ & $10^{\circ} \mathrm{C}$ & $20^{\circ} \mathrm{C}$ & $30^{\circ} \mathrm{C}$ & $40^{\circ} \mathrm{C}$ & $50^{\circ} \mathrm{C}$ \\
\hline 1 & 76.150 & 71.822 & 68.034 & 66.194 & 65.328 & 63.164 \\
2 & 101.455 & 98.320 & 95.185 & 94.244 & 93.617 & 92.050 \\
3 & 212.223 & 203.694 & 195.165 & 192.606 & 190.901 & 186.636 \\
4 & 295.347 & 289.123 & 282.899 & 281.031 & 279.787 & 276.674 \\
\hline
\end{tabular}

difficult to measure accurately compared with the frequencies and the mode shapes. A large uncertainty in modal damping might mask the temperature effects.

Xia et al. [28] constructed a simply supported RC slab which measures $3200 \mathrm{~mm}$ long, $800 \mathrm{~mm}$ wide, and $120 \mathrm{~mm}$ thick with $100 \mathrm{~mm}$ overhang at each end, as shown in Figure 2 . This study aims to investigate the variation of the structural vibration characteristics with respect to different temperatures. Sets of modal testing were carried out hourly from 8:00 am to 22:00 pm on February 11, 2009. The locations of the acceleration sensors are shown in Figure 3. At the same time, structural temperatures were automatically recorded from the embedded thermocouples every 2 min. Figure 4 illustrates the variation of the measured first natural frequency with respect to temperatures measured from the thermocouples. It clearly shows that the frequency of the structure decreases when temperature goes up before noon while the frequency increases as temperature drops down in the afternoon, as observed by many researchers. However, the temperature effect on damping ratios is not so obvious. Figure 5 illustrates the variation of the first two modal damping ratios extracted from measurement with respect to time. It was found that damping ratios increase slightly when the temperature rises. Since the variation of temperature here is not significant and the uncertainty level of measurement of damping is relatively high, the change of damping may be masked by the measurement noise.

Xia et al. [30] examined the effect of temperature on vibration properties of different structures made of different materials, in particular, steel, aluminum, and RC, through laboratory studies. An RC slab, a steel beam, and an aluminum beam were constructed outside the laboratory and exposed to solar irradiation. The RC slab is simply supported while the support conditions of the two metallic beams are cantilever. Temperature variations were recorded from the installed thermocouples. Modal testing was carried out using an instrumented hammer. The outcomes indicated that all natural frequencies of the three beams decreased with an increase in surface temperature and increased with a decrease in surface temperature. The variation trend matched the surface temperature very well although the frequency variations were very small. The frequency variations of the $\mathrm{RC}$ slab are much larger than those of the metallic beams. No clear correlation between damping ratios of the three beams and temperature can be found, indicating that temperature has little effect on damping ratios.
In addition, Sun et al. [42, 43] performed an experimental study on correlation between dynamic properties of a cable-stayed bridge model and its structural temperature. The results indicate a tendency that the frequency of the cable-stayed bridge model decreases with the increase of temperature.

3.3. Field Monitoring Approach. The temperature variations in bridges are affected by air temperature, wind, humidity, intensity of solar radiation, material type, and so forth [44]. The vibration properties of bridges are governed not only by material characteristics and geometrical configurations but also by boundary conditions and load cases. The above two reasons make the correlations between temperatures and vibration properties of long-span bridges difficult to extract by theoretical derivation, numerical simulation, and laboratory test. Field measurement that monitored the temperatures and vibration responses of a bridge by sensors installed on it can give the most objective data subjected to real service circumstance. The correlations between temperatures and vibration properties deduced from those data may be in turn more convincing. With the development of sensor and computer technology, continuous field measurements of temperatures and vibration responses in structures have been carried out extensively in various bridges.

In the 1980s, being limited to the measurement instruments, long-term dynamic tests of bridges are seldom. Turner [45] tested a three-span concrete foot-bridge which consists of one central $16 \mathrm{~m}$ and two $8 \mathrm{~m}$ side spans. Results showed that the natural frequencies of this small bridge appeared unaffected by temperature changes. Then, he further studied a highway bridge and stated that there is "some evidence" to show that the natural frequencies of the bridge structure they tested did not change more than $0.5 \%$ as a result of environmental effects [46]. In 1988, Askegaard and Mossing [47] tested a three-span RC footbridge for a three-year period, and about $10 \%$ seasonal changes in the frequencies were repeatedly observed for each year. The authors concluded that the changes were partially attributed to the variation of ambient temperature.

Wood [48] reported that bridge responses were closely related to the structural temperature based on vibration tests of five bridges in the United Kingdom. Here, the test results are different from those obtained by Turner. This is because the span of the bridge tested by Turner is small, and the effect of temperature on the dynamic characteristics of the bridge is slight, while the bridges tested by Wood are long-span bridges, and the effect of temperature on the dynamic characteristics of these bridges is obvious. Analyses based on the data compiled suggested that the variability of the asphalt elastic modulus due to temperature effects is a major contributor to the changes in the structural stiffness. Temperature variation not only changes the material stiffness but also alters the boundary conditions of a system.

Rohrmann et al. $[49,50]$ presented the results of tests performed on a 7-span highway bridge in Berlin over a sixmonth time period. Those studies showed that the temperature effects on the dynamics bridge cannot be neglected. 


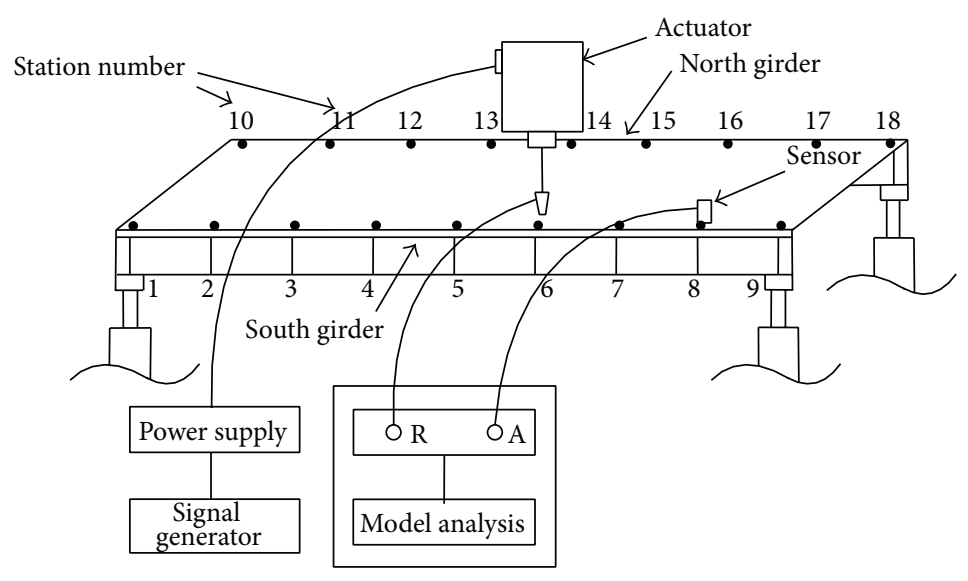

R: reference channel

A: active channel

FIGURE 1: Test setup for model plate-girder bridge [27].

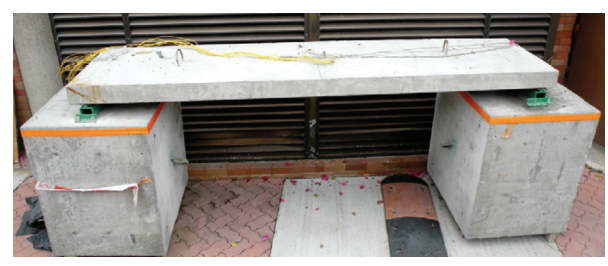

Figure 2: The RC slab [28].

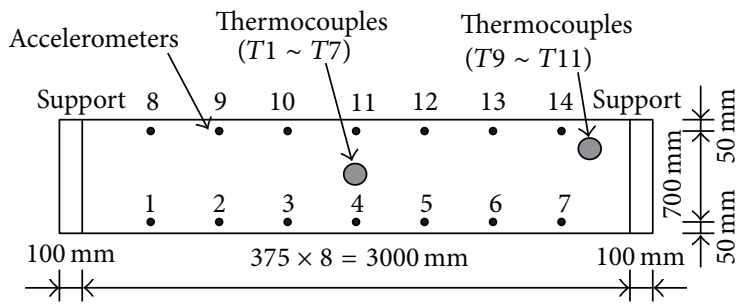

FIGURE 3: Locations of the acceleration sensors [28].

The natural frequencies increase as the mean temperature decreases. On a time scale of days these tests indicated the first mode frequency varying from 2.3 to $2.8 \mathrm{~Hz}$. DeWolf et al. $[51,52]$ studied the interaction between the variable temperature and the governing natural frequencies of a two span skewed composite steel-girder bridge. It was found that the maximum changes in the natural frequencies, based on comparison with the baseline frequencies at $55^{\circ} \mathrm{F}\left(12.8^{\circ} \mathrm{C}\right)$, were $11.6 \%$ for the first frequency, $15.4 \%$ for the second frequency, and $9.4 \%$ for the third frequency, respectively. These occurred at the temperatures of $4^{\circ} \mathrm{F}\left(-15.6^{\circ} \mathrm{C}\right), 4^{\circ} \mathrm{F}\left(-15.6^{\circ} \mathrm{C}\right)$ and $15^{\circ} \mathrm{F}\left(-9.4^{\circ} \mathrm{C}\right)$, respectively. As noted previously, the natural frequency increased with decreasing temperature. Between the temperature at $55^{\circ} \mathrm{F}\left(12.8^{\circ} \mathrm{C}\right)$ and $10^{\circ} \mathrm{F}\left(-12.2^{\circ} \mathrm{C}\right)$, the maximum percent difference of modal displacements for the first bending mode, the first torsional mode, and the second bending mode are $22.1,100$, and $47.1 \%$, and the percent

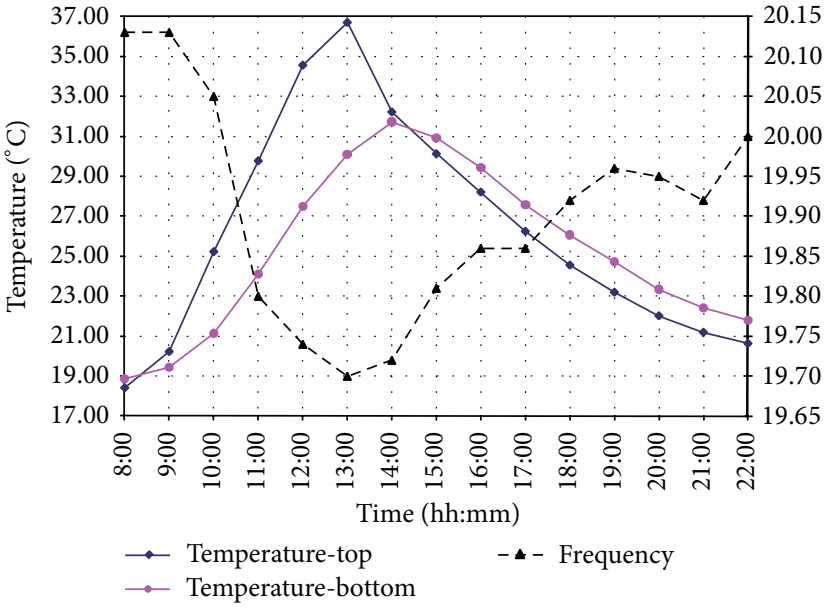

FIGURE 4: Variation of the first frequency versus temperatures [28].

difference in the diagonal terms of the modal flexibility is $20.8,34.1$, and $22.3 \%$ for the first, second, and third mode. The modal flexibility for the two different temperature levels produces significantly larger changes than the natural frequencies.

Researchers from Los Alamos National Laboratory [5355] performed several tests on the Alamosa Canyon Bridge located in southern New Mexico. This bridge has seven independent spans and each span consists of a concreted deck supported by six W30 $\times 116$ steel girders. The results revealed that the first three natural frequencies of the bridge varied about $4.7 \%, 6.6 \%$, and $5.0 \%$ during a $24 \mathrm{~h}$ period as the temperature of the bridge deck changed by approximately $22^{\circ} \mathrm{C}$. The temperature gradient largely influences the variation of the fundamental frequency. They also found that a significant artificial cut in the I-40 Bridge over the Rio 


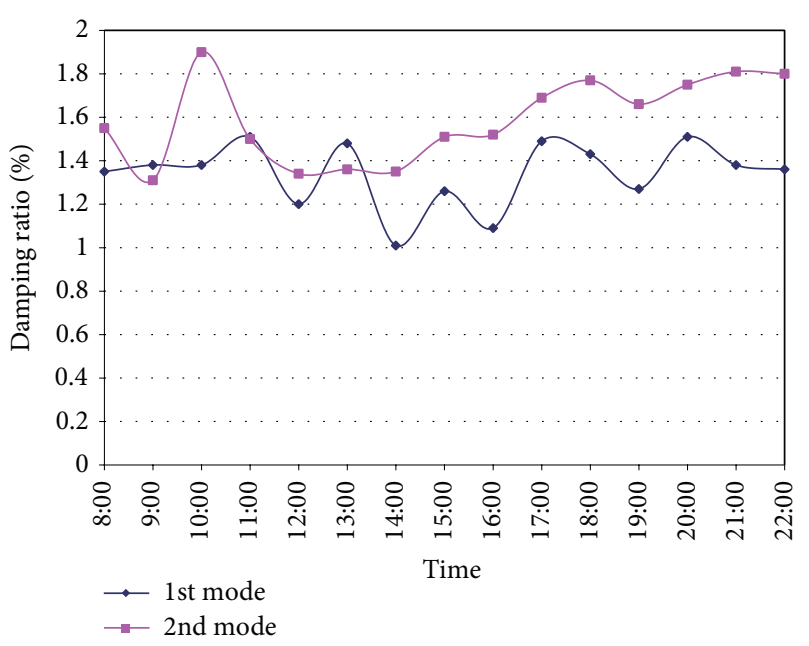

FIGURE 5: Variation of the damping ratios [28].

Grande caused only insignificant frequency changes [56]. Wahab and De Roeck [57] investigated the seasonal effect of temperature variations on natural frequencies of a concrete bridge and found that changes in natural frequencies of the bridges can be up to 5-6\% during a year. Roberts and Pearson [58] described a monitoring program on a 9-span, $840 \mathrm{~m}$ long bridge. It was found that normal environmental changes could account for changes in frequencies of as much as 3-4\% during the year.

Alampalli [59] conducted several tests over nine months on a steel-stringer bridge with a concrete deck to examine the sensitivity of measured modal parameters to variations resulting from test and in-service environmental conditions. The results confirmed that, for the bridge with a span of $6.76 \mathrm{~m}$ and a width of $5.26 \mathrm{~m}$, the natural frequency changes caused by the freezing of the bridge supports were an order of magnitude larger than the variation introduced by an artificial saw cut across the bottom flanges of both girders. It was suggested that bridges should be monitored for at least one complete cycle of in-service conditions before establishing warning triggers or using damage assessment algorithms so that the influence of temperature can be well understood. Rohrmann et al. [60] further studied the thermal effect on modal frequencies of an eight-span prestressed concrete bridge by using three-year continuous monitoring data in an attempt to establish functional proportionality between the temperature variations and changing natural frequencies. They concluded that vibration frequencies decrease with the temperature increase.

Peeters et al. [61-63] conducted a study devoted to monitoring the effect of changing environmental conditions on structural vibration properties on the Z24 Bridge in Switzerland. It was continuously monitored for nearly a year. It was reported that the first four vibration frequencies varied by $14 \%-18 \%$ during the 10 months. It was also found that the frequencies of all the modes analyzed, except the second mode, decreased with the temperature increase. The second mode frequency, however, increased with increasing temperatures (for positive temperatures). In particular, a bilinear relationship was observed between the measured frequencies and temperature. There was a clear linear relationship above the freezing temperature $\left(0^{\circ} \mathrm{C}\right)$ and a different linear correlation below the freezing temperature. It was demonstrated that this bilinear behavior was attributed to the asphalt layer on the deck. Although the asphalt layer did not contribute to the overall stiffness at warm temperatures, it added significant stiffness to the bridge at cold temperatures. Similar outcomes were also found in a ballasted railway bridge in Sweden by Gonzales et al. [29]. The natural frequencies of the bridge increase by $15 \%$ and $35 \%$ for the first vertical bending and first torsional modes during the cold period of the year, respectively. Furthermore, the increase in natural frequencies took place only after the temperatures had dropped below $0^{\circ} \mathrm{C}$ for a number of days, as shown in Figure 6.

$\mathrm{Ni}$ et al. [64] investigated the influence of temperature on modal frequencies for the cable-stayed Ting Kau Bridge (Hong Kong) which has been instrumented with a long-term SHM system. Based on one-year measurement data obtained from 45 accelerometers and 83 temperature sensors, the modal frequencies and temperatures of the bridge at various locations were obtained at one-hour intervals to cover a full cycle of in-service/operating conditions. It was found that the environmental temperature changes from 2.83 to $53.46^{\circ} \mathrm{C}$ account for variation in modal frequencies with variance from $0.20 \%$ to $1.52 \%$ for the first ten modes, which may mask the modal changes caused by structural damage. Desjardins et al. [65] examined the variations in frequencies of the Confederation Bridge (made of prestressed concrete) over a 6-month period. They reported a clear trend of reduction in the modal frequencies by about $4 \%$, when the average temperature of the concrete of the bridge varied from -20 to $+25^{\circ} \mathrm{C}$.

Liu and DeWolf $[17,66]$ explored how temperature variations influence the modal properties based on frequency and temperature measurements obtained over the period of one year from a long-term SHM system that was installed on an in-service curved bridge. The curved bridge is $235 \mathrm{~m}$ long, with three unequal-length continuums of 58,88 , and $88 \mathrm{~m}$, respectively. The superstructure is a five-cell curved prismatic box girder. The results indicated that the long-term variations of modal frequencies have a reciprocal relation with respect to the variation in the in situ concrete temperature for all three measured modes. The natural frequencies varied by a maximum of $6 \%$ in a peak to peak temperature range of $70^{\circ} \mathrm{F}$ during one full year. The higher modal frequency is less sensitive to temperature changes and the bending modes are more easily affected by temperature than torsion modes, which is similar to that obtained by Kim et al. [67] in an experimental study of a model plate-girder bridge. In addition, the results reported in this study argued that use of the natural frequencies alone is not sufficient for damage detection because of their sensitivity to temperature and the influence of temperature on the natural frequency is likely structure specific.

Ding et al. $[68,69]$ observed the daily and seasonal correlations of frequency-temperature using 215 days of 


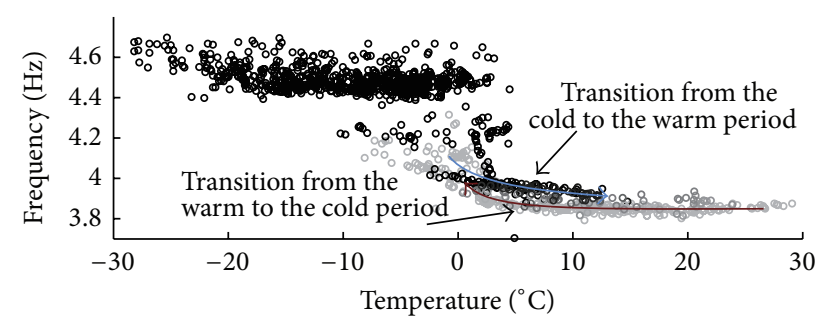

FIGURE 6: The variation in the frequency of the first vertical bending mode as function of temperature [29].

health monitoring data obtained on the Runyang Suspension Bridge. The bridge is a single-span steel suspension bridge with the main span $1,490 \mathrm{~m}$. The aerodynamically shaped closed box steel girder is $36.3 \mathrm{~m}$ wide and $3.0 \mathrm{~m}$ high. From the daily correlations of temperature-frequency, it was reported that an overall decrease in modal frequency was observed with the increase in temperature of the bridge and measured modal frequencies of higher modes are more sensitive to ambient temperatures. About $2 \%$ variation in the first six modal frequencies during a period of 10 months was found, as the ambient temperature of the steel bridge varied from -5 to $+50^{\circ} \mathrm{C}$. Moreover, the conclusion that the daily averaged modal frequencies of vibration modes have remarkable seasonal correlations with the daily averaged temperature was also deduced.

Moser and Moaveni [32] presented results from a continuous monitoring system installed on the Dowling Hall Footbridge on the campus of Tufts University. The bridge is a two-span continuous steel frame bridge of $44 \mathrm{~m}$ long and $3.7 \mathrm{~m}$ wide. It was observed that (1) the identified natural frequencies increase as temperatures decrease, (2) this effect is more significant when the temperatures are below the freezing point resulting in a nonlinear relationship, and (3) Modes 1, 3, and 4 show more clear correlation with temperature while Modes 2, 5, and 6 show more scatter. One explanation for the third observation is that Modes 2, 5 , and 6 are identified with larger estimation uncertainties. The natural frequencies of the first six identified modes varied by $4-8 \%$ while temperatures ranged from -14 to $39^{\circ} \mathrm{C}$, and the relationship between identified natural frequencies and measured temperatures was nonlinear. However, no obvious variation in damping ratios and mode shapes was observed. One possible reason is that those parameters are not identified with enough precision.

Xia et al. [30] investigated the correlations between temperatures and vibration properties of the Tsing Ma Suspension Bridge, which has a total span of 2,132 $\mathrm{m}$ and carries highway and railway tracks. Figure 7 shows the variations in the first four vertical frequencies and temperature on January 17,2005 . It was found that all frequencies generally decrease when the temperature goes up before noon, whereas they increase as the temperature drops in the afternoon although the variations are quite small. The results are consistent with that obtained from the laboratory model [28]. The minimum frequencies and the maximum temperatures do not occur at the same time, and the time difference is about $3 \mathrm{~h}$. Two reasons were deduced. The first one is that the temperature is nonuniformly distributed across the bridge and the frequencies are global properties and are associated with the temperature distribution of the entire structure. And the second one is that the variations in temperature caused internal stresses of the components changes, for example, the cables. The variation trends of the vertical modal frequencies are very similar and the maximum variations are about $1-1.5 \%$. No clear correlation between damping ratios and temperature was observed.

Mosavi et al. [70] monitored the response of a skewed two-span steel-concrete composite bridge in North Carolina during a $24 \mathrm{~h}$ period to address possible reasons for the daily variations in modal frequencies of the bridge. An almost 1-2\% change in natural frequencies was investigated in all modes of the bridge from night to noon, while the natural frequencies did not change significantly from night to morning. The shifts in the natural frequencies from night to noon were coincident with an inversion of the temperature gradients in the composite cross section of the bridge from night to noon. It was argued that this inversion of the temperature gradients from night to noon is the main reason for a relatively large upward deformation of the steel girders and variations of the measured natural frequencies during this time.

Besides, other research groups, like Lloyd et al. [71, 72], Kullaa et al. [73], Breccolotti et al. [74], Song and Dyke [75], Siddique et al. [26], Yang et al. [76], Di, et al. [77], Zabel et al. [78], Wang et al. [79], Cury et al. [80], and Koo et al. [81], also carried out structural vibrations and temperatures tests on different types of bridges. The similar conclusion that vibration properties of long-span bridges are significantly impacted by varying temperatures was drawn.

\section{Progress of Quantitative Model}

The trend analysis can reveal the degree that the vibration properties are affected by temperature variations. Most studies in the above literature indicate that the natural frequencies decrease as the temperature rises. Those results that are directly deduced from simulated or measurement data are bridge-dependent and time-dependent. For different bridges, the changes of natural frequencies per temperature unit are different. Even using the data obtained from an identical bridge at different times, the extracted outcomes may be different. To eliminate the environmental effects in vibration-based damage detection, the quantitative model that is used to quantify the variations of vibration properties under temperature changes becomes necessary. The SHM systems installed on large-scale bridges permanently obtain long-term vibration data and corresponding temperature data, which provides a great opportunity for quantitative understanding and modeling of the effect of temperature on modal properties. Three types of quantitative models including linear model, nonlinear model, and learning model were developed in the past few years. 


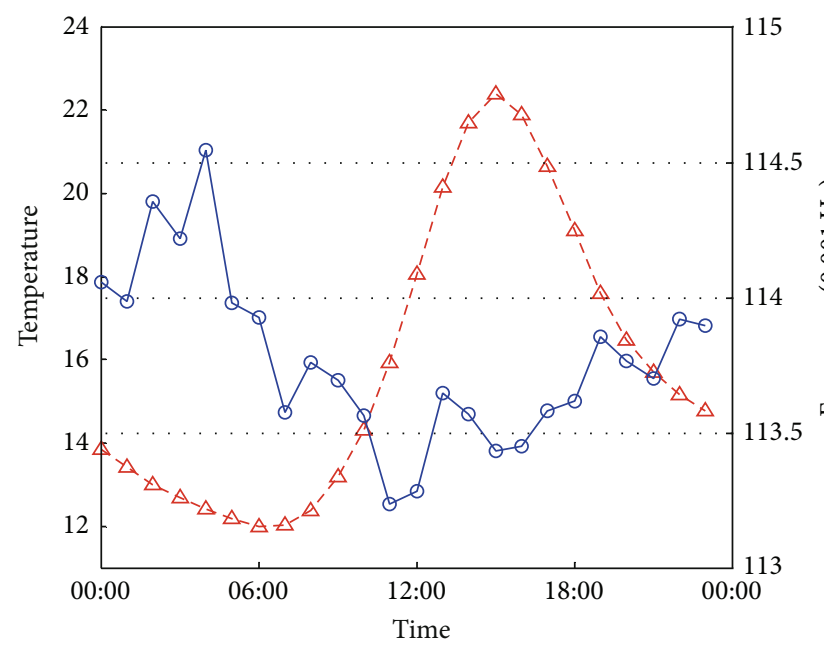

(a)

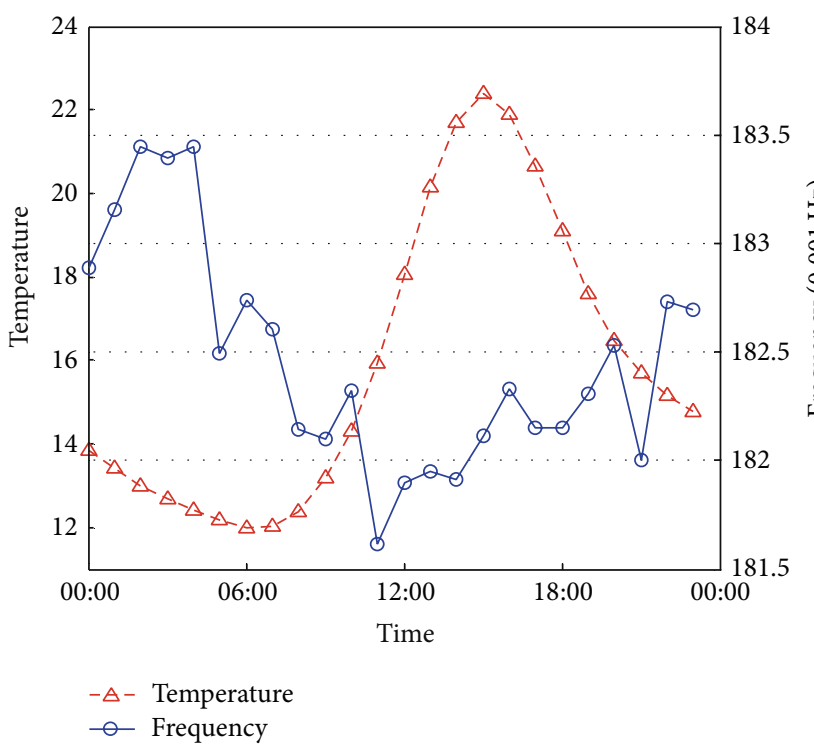

(c)

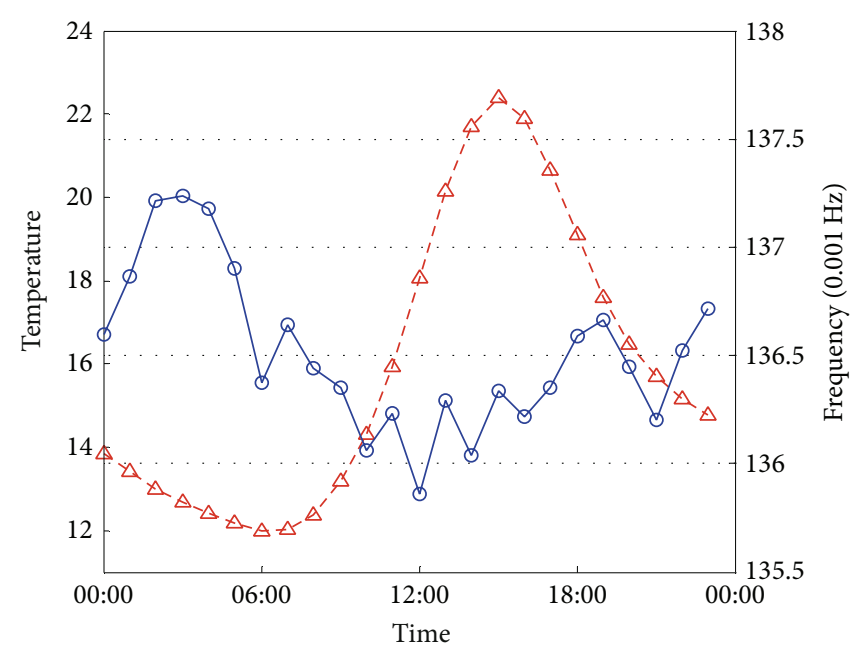

(b)

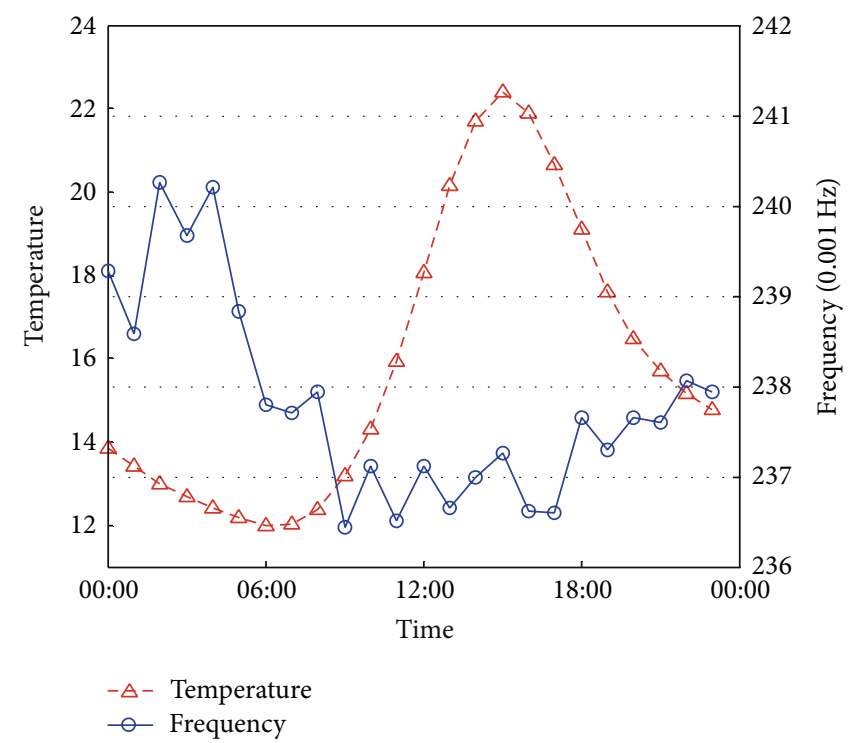

(d)

FIGURE 7: Variations in frequencies with respect to the temperature of the Tsing Ma Bridge on January 17, 2005 ((a) 1st vertical, (b) 2nd vertical, (c) 3rd vertical, and (d) 4th vertical) [30].

4.1. Linear Model. The linear model assumes that the vibration properties change with temperature linearly. The coefficients of the linear model are usually estimated by regression methods. This model is consistent with simplified theoretical formulation and very easy to implement.

Sohn et al. [31, 82] proposed a linear adaptive filter that accommodates the changes in temperature to the damage detection system of a large-scale bridge by introducing the assumption that changes in the modal parameters are linearly proportional to changes in temperature. The linear filter models the relationship between the selected bridge temperature inputs $x$ and its measured fundamental frequency $y$ as a linear function

$$
y=x w+\varepsilon
$$

where $w$ is a column vector of coefficients that weighs each temperature input and $\varepsilon$ is the filter error. With $n$ observations

$$
\begin{aligned}
y=\left[\begin{array}{c}
y(1) \\
y(2) \\
\vdots \\
y(n)
\end{array}\right], \quad X=\left[\begin{array}{ccccc}
1 & x_{1}(1) & x_{2}(1) & \cdots & x_{r}(1) \\
1 & x_{1}(2) & x_{2}(2) & \cdots & x_{r}(2) \\
\vdots & \vdots & \vdots & \cdots & \vdots \\
1 & x_{1}(n) & x_{2}(n) & \cdots & x_{r}(n)
\end{array}\right], \\
\varepsilon=\left[\begin{array}{c}
\varepsilon(1) \\
\varepsilon(2) \\
\vdots \\
\varepsilon(n)
\end{array}\right],
\end{aligned}
$$

where $r$ represents the number of inputs. 


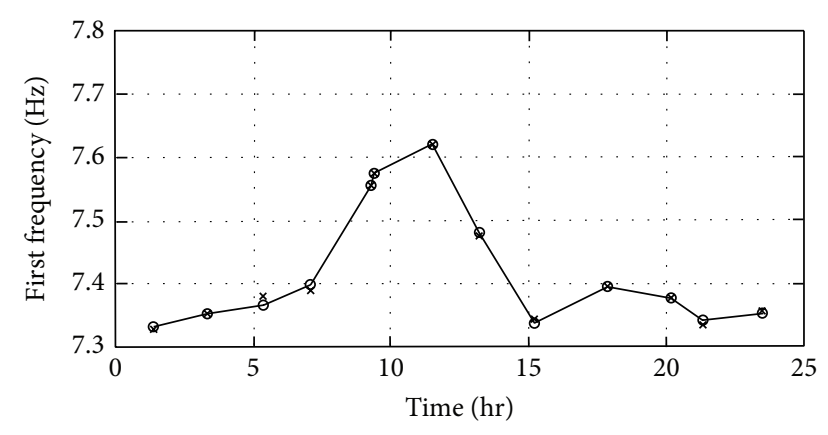

- Estimated from the regression model

$\times$ Measured (first data set)

FIGURE 8: Reproduction of the first mode frequency using a linear filter [31].

The Least-Mean-Squares (LMS) error minimization was employed to estimate the filter coefficients. Data from the Alamosa Canyon Bridge in the state of New Mexico were used to demonstrate the effectiveness of the adaptive filter. The first dataset from 1996 was used to train the adaptive filter, while the second dataset from 1997 was used to test the prediction performance. A linear filter with two spatially separated and two temporally separated temperature measurements was then developed. The reproduction of the first mode frequency is shown in Figure 8. It indicates that a linear adaptive filter with four temperature inputs could reproduce the natural variability of the frequencies with respect to time of day reasonably well. Then, the regression model can be used to establish confidence intervals of the frequencies for a new temperature profile.

Peeters et al. [62, 63] proposed a dynamic linear regression model called ARX to filter out the temperature effects from the measured frequencies using monitoring data obtained from the healthy Z24-Bridge in Switzerland. Singleinput and single-output (SISO) ARX models were constructed for the first four fundamental frequencies, describing the relation between one input temperature and one output frequency. The loss function value and the final prediction error were used as the quality criteria to find a good model. The measurement data of the Z24-Bridge were split in two parts: an estimation part and a validation part. The estimation data were used to estimate the ARX model, whereas the validation data were applied to validate the model. It was validated that an ARX model that includes the thermal dynamics of the bridge is superior to a "static" regression model. Also, it turned out that a temperature measurement at one location was sufficient to find an accurate model. The ARX model can be used for simulating the frequencies when new temperature measurements are fed to the model. If a new measured frequency lies outside the estimated confidence intervals, it is likely that the bridge is damaged. In case of the Z24-Bridge and the applied damage scenarios, the damage was successfully detected.

It is interesting that the regression approaches performed by Sohn et al. [31] and Peeters et al. [62] were compared by Sohn [83]. It was pointed out that the Peteers' work emphasizes the thermal dynamics of the bridge by using a single temperature measurement with multiple time lags (the temporal variation of temperature), while the work by Sohn et al. uses temperature readings from multiple thermocouples to take into account the temperature gradient across the bridge (the spatial variation of temperature) as well as the temporal variation. The comparison of these two approaches clearly demonstrated that the two models are problemspecific. Because the temperature of the Alamos Canyon Bridge can easily go above $45^{\circ} \mathrm{C}$, the bridge experiences a large temperature gradient across the bridge throughout the day. Therefore, it is feasible that the spatial variation of the bridge temperature might have been the main driving factor for the frequency variation. On the other hand, the magnitude of the Z24 Bridge, which had a $30 \mathrm{~m}$ long main span and two $20 \mathrm{~m}$ long side spans with $8.6 \mathrm{~m}$ width, is certainly larger than the Alamos Canyon Bridge. Therefore, it is possible that it takes a longer time before the temperature affected the dynamic properties of the bridge and the time-lag information of the temperature is more important for the Z24 Bridge than the Alamos Canyon Bridge.

A reinforced concrete slab, which was constructed and placed outside the laboratory, has been periodically vibration tested by Xia et al. [34] for nearly two years. Linear regression models between modal properties and temperature were proposed. The corresponding linear regression model is taken as

$$
q=\beta_{0}+\beta_{t} t+\varepsilon_{f}
$$

where $q$ represents the dynamic parameter such as frequency and percentage damping ratio, $\beta_{0}$ (intercept) and $\beta_{t}$ (slope) are regression coefficients, and $\varepsilon_{f}$ is the error. $\beta_{t} / \beta_{0}$ indicates the percentage of the frequency change when the structural temperature increases by unit degree Celsius. With leastsquares fitting, the regression coefficients and confidence bounds are obtained. The correlation coefficient was used to examine the goodness of fit of the linear relation between frequencies and temperature. The results implied that there is a good linear correlation between the two variables. It is worth noting that the estimated linear regression function agrees well with the theoretical model of (4), which demonstrates the reliability of the theoretical derivation. Then, this linear regression model was utilized to examine the relation between the frequencies and the structural temperature of three beam models that are made of steel, aluminum, and reinforced concrete (RC) [30]. The correlation coefficients of the first four natural frequencies of the steel beam are -0.93 , $-0.99,-0.96$, and -0.97 , respectively, implying a very good linear correlation between the average temperature and the natural frequencies. The regression coefficients of the three structures were also obtained and listed in Table 2 for each mode. The variations of modal frequencies per degree are very close to half of the modulus thermal coefficients of the material. Subsequently, the linear regression model was applied to the first four vertical modal frequencies of the Tsing Ma Suspension Bridge in 4 days, as shown in Figure 9. Good linear correlation can be observed from the figure. The averaged value $\left(\beta_{t} / \beta_{0}\right)$ for the four modes is very close to 


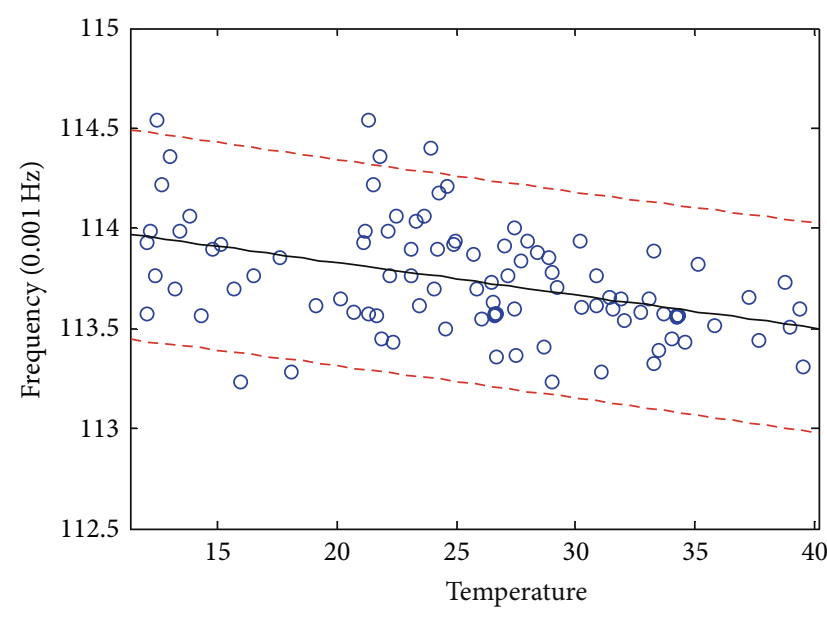

(a) 1st vertical mode

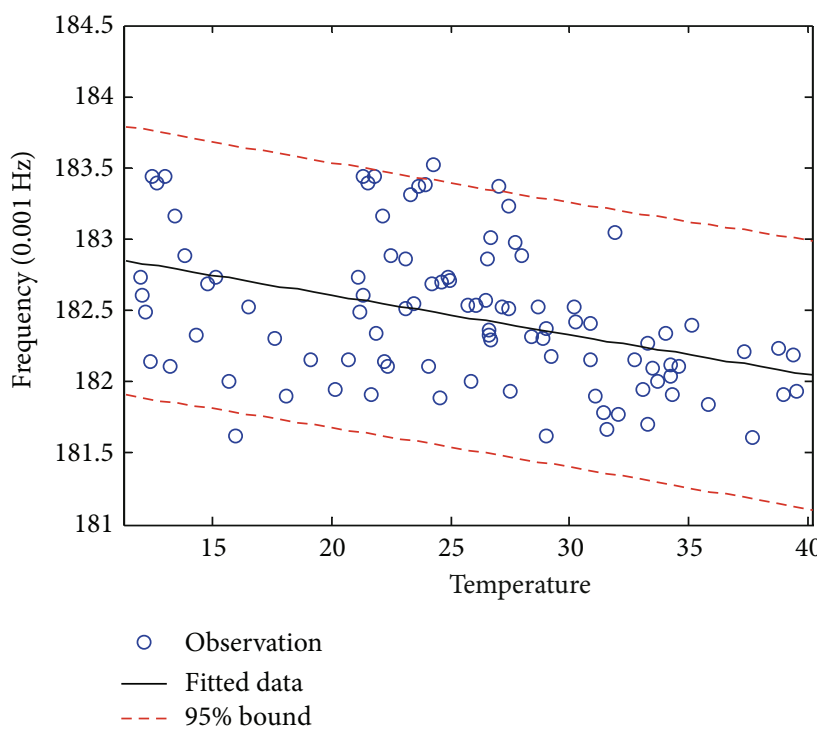

(c) 3rd vertical mode

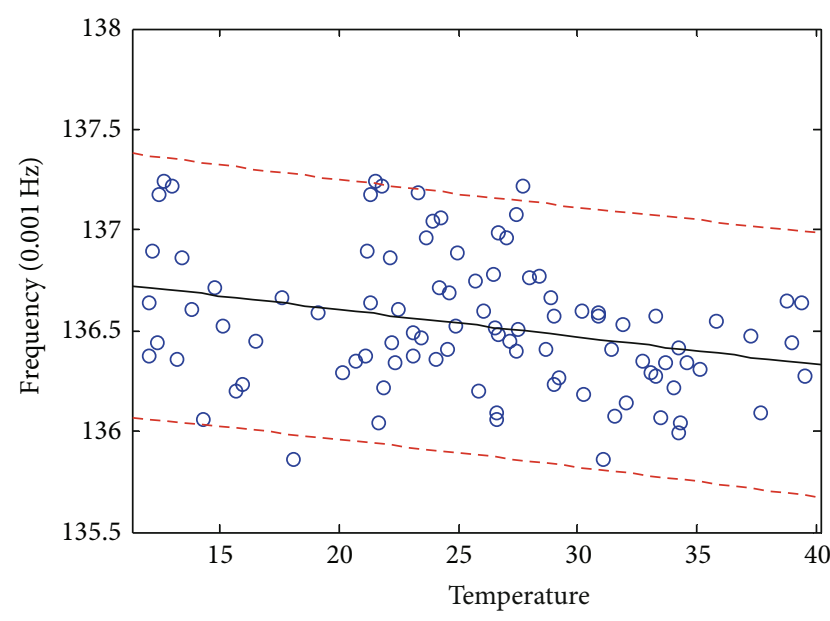

(b) 2nd vertical mode

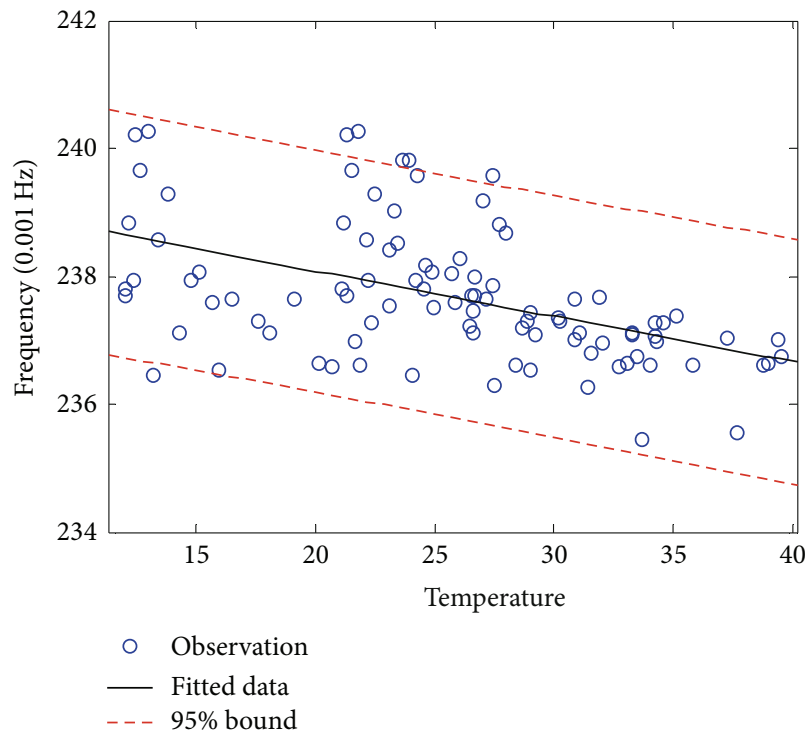

(d) 4 th vertical mode

FIgURE 9: Relation of natural frequencies to temperature of the Tsing Ma Bridge [30].

that of the laboratory tested steel beam and also to half of the modulus thermal coefficients of steel. Both laboratory model results and real bridge results demonstrated that variations in the bending frequencies of the structures are mainly caused by the change in the modulus of the material although the two structures are quite different in terms of size, type, and boundary conditions. Besides, applying the linear regression model to the damping data showed that their correlation coefficients are $0.10,0.07,-0.11$, and -0.33 , respectively.

Similarly, Liu and DeWolf $[17,84]$ developed a linear regression model with a 5\% estimate error to represent the three natural frequencies of a three-span curved posttensioned box concrete bridge located in Connecticut as a function of temperature. The model is mathematically described as

$$
F_{i}=f_{i}+a T
$$

where $f_{i}$ is mean natural frequency, $T$ denotes concrete temperature, and $F_{i}$ represents natural frequency at temperature $T$. The parameter $a$ is determined from the measured monitoring data. Based on a full year data beginning with January 2002 recorded by a long-term health monitoring system, the functions of the first three natural frequencies are

$F_{1}$

$=1.5588-0.007 \mathrm{~T}$ (first natural frequency: $1.519 \mathrm{~Hz})$,

$F_{2}$

$=2.1584-0.008 \mathrm{~T}$ (second natural frequency: $2.11 \mathrm{~Hz}$ ),

$F_{3}$

$=3.6391-0.007 \mathrm{~T}$ (third natural frequency: $3.59 \mathrm{~Hz}$ ). 
TABLE 2: Regression coefficients of the models (Xia et al. [30]).

\begin{tabular}{lccccccccc}
\hline \multirow{2}{*}{ Mode number } & \multicolumn{3}{c}{ Steel beam } & \multicolumn{3}{c}{ Aluminum beam } & \multicolumn{3}{c}{ Concrete beam } \\
& $\beta_{0}$ & $\beta_{t}$ & $\beta_{t} / \beta_{0}$ & $\beta_{0}$ & $\beta_{t}$ & $\beta_{t} / \beta_{0}$ & $\beta_{0}$ & $\beta_{t}$ \\
\hline 1 & 3.69 & -0.0014 & $-3.78 \times 10^{-4}$ & 3.28 & -0.0024 & $-7.31 \times 10^{-4}$ & 20.65 & -0.029 & $-1.4 \times 10^{-3}$ \\
2 & 23.79 & -0.0035 & $-1.47 \times 10^{-4}$ & 20.37 & -0.0086 & $-4.22 \times 10^{-4}$ & 83.74 & -0.089 & $-1.1 \times 10^{-3}$ \\
3 & 66.64 & -0.0132 & $-1.98 \times 10^{-4}$ & 60.01 & -0.0163 & $-2.72 \times 10^{-4}$ & & \\
4 & 140.06 & -0.0253 & $-1.81 \times 10^{-4}$ & 117.63 & -0.0470 & $-4.00 \times 10^{-4}$ & & \\
\hline
\end{tabular}

The proposed models were used for comparison with data collected in 2005. Results of the hypothesis test showed that they both conform to the normality distribution, but they do not always have identical medians.

4.2. Nonlinear Model. Although linear models are simple and intuitionistic, the responses of long-span bridges, particularly cable-supported bridges, are nonlinear. The error that generates from linear models may mask the shift of vibration properties caused by structural damages. From this point of view, the nonlinear models are more reasonable.

Ding and Li [68] proposed a polynomial regression model to describe the frequency-temperature seasonal correlations of the Runyang Suspension Bridge, which can be mathematically described as

$$
f(T, n)=p_{n} T^{n}+p_{n-1} T^{n-1}+\cdots+p_{2} T^{2}+p_{1} T^{1}+p_{0},
$$

where $T$ is the daily averaged value of temperature, $f$ denotes the daily averaged values of the frequency, $n$ means the order of polynomial regression model, and $p_{i}(i=0 \sim n)$ represents the coefficient of the regression model. The 175day monitoring data were discontinuously extracted from the total 215-day data for training the model and the other 40-day monitoring data were used for testing the prediction capability. By increasing the number of $n$ from 1 to 10 , the regression models were formulated and the relative errors of measured and predicted frequencies were obtained. The best order $n$ of the regression model was selected as 6 for this bridge. The 40-day temperature data were fed into the trained regression model to generate the prediction values of modal frequency which were compared with the measured values to evaluate the prediction capability. The result demonstrated that the developed polynomial regression model exhibits good capabilities for mapping between the temperature and measured modal frequency.

Using results from a vibration-based continuous monitoring system deployed on the Dowling Hall Footbridge at Tufts University in Medford, Moaveni et al. [32, 85] proposed four models including a static linear model, an ARX model, a bilinear model, and polynomials of various orders to represent the relationship between the identified natural frequencies and measured temperatures. Through correlation coefficient, three records were used to model the relationship between the identified natural frequencies and the measured temperatures. The estimation error variance and two objective criteria including the Akaike's Information Criterion (AIC) and the Bayesian Information Criterion
(BIC) were employed as the model quality metric. After evaluating those candidate models, the fourth-order polynomial without cross terms was selected as the final model, while the bilinear model also performs well and shows promise for environmental modeling near the freezing point. The validity of the selected fourth-order model was assessed based on separate sets of validation data from two different datasplitting methods. Figure 10 displays one of the comparisons. It was demonstrated that the model can be applied to the future data with almost the same accuracy that it fits the modeling data as long as future temperatures are not outside the range of modeling temperatures.

4.3. Learning Model. The temperature distribution in a bridge is governed by air temperature, solar radiation, wind speed, and so on, all of which vary in a random manner. As a result, the temperature distribution in a bridge is random. The measurement error caused by uncertainties in actual tests are stochastic, which induces the tested vibration properties of a bridge, notably natural frequency, are scattered under the same temperature. For these two reasons, the reliability is questionable when the relationship between temperatures and vibration properties of long-span bridges is described by simple linear regression model or polynomial regression model. To discriminate the variations of vibration properties due to temperature changes from those caused by structural damage, the sophisticated models should be developed, which are called learning models in this paper. The learning models integrated intelligent algorithm and show a better robustness and performance to predict the vibration properties of bridges under different temperatures.

Ni et al. [64] applied the support vector machine (SVM) technique to formulate regression models which quantify the effect of temperature on modal frequencies for the cablestayed Ting Kau Bridge (Hong Kong) based on long-term monitoring data. In order to achieve a trade-off between simulation performance and generalization, only a portion of the measurement data was employed to train the SVM models, and the remaining measurement data was used for model validation. A squared correlation coefficient was defined for optimizing the SVM coefficients to obtain good generalization performance. The results obtained by the SVM models were compared with those produced by a multivariate linear regression model and showed that the SVM models exhibit good capabilities for mapping between the temperature and modal frequencies. In this model, the average temperature was used, but several studies showed that the measured temperatures from different locations of 


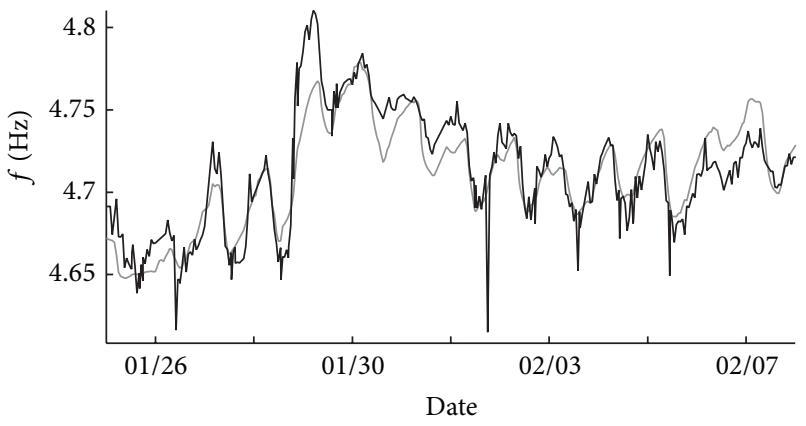

(a)

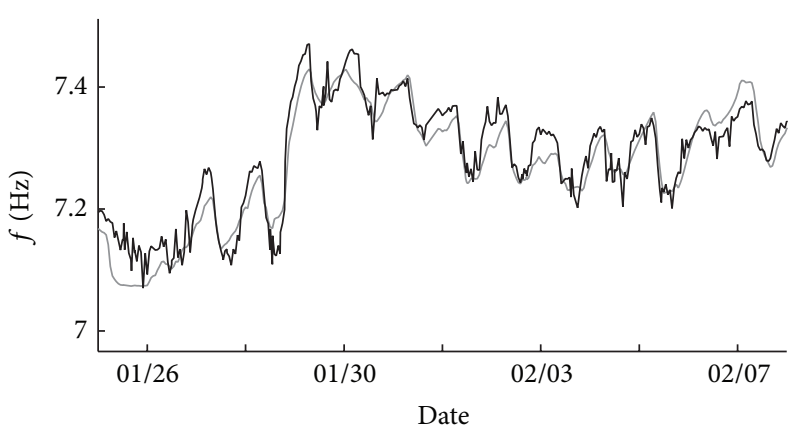

(c)

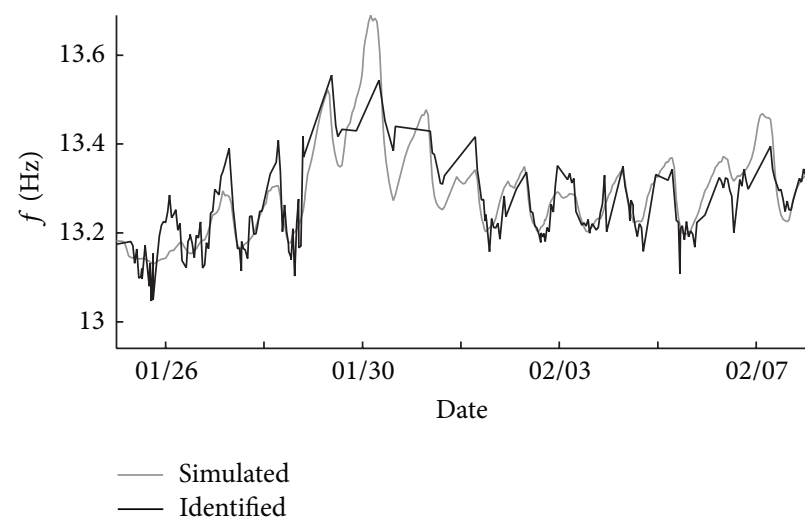

(e)

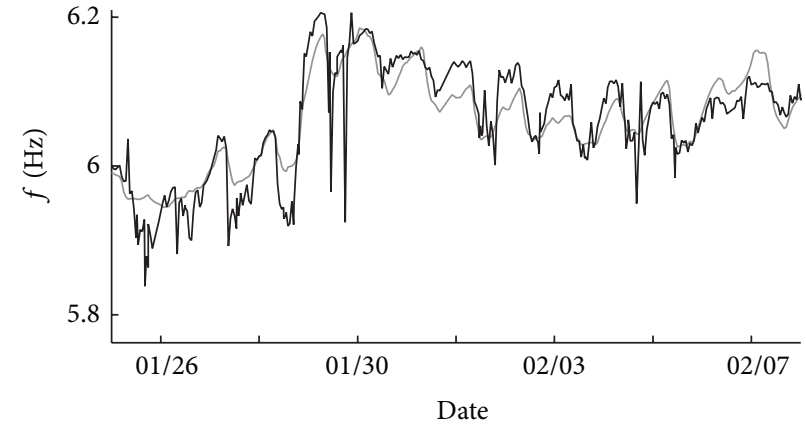

(b)

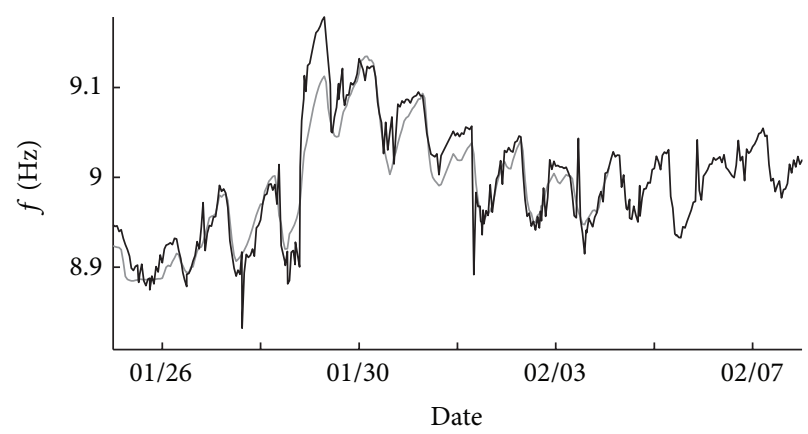

(d)

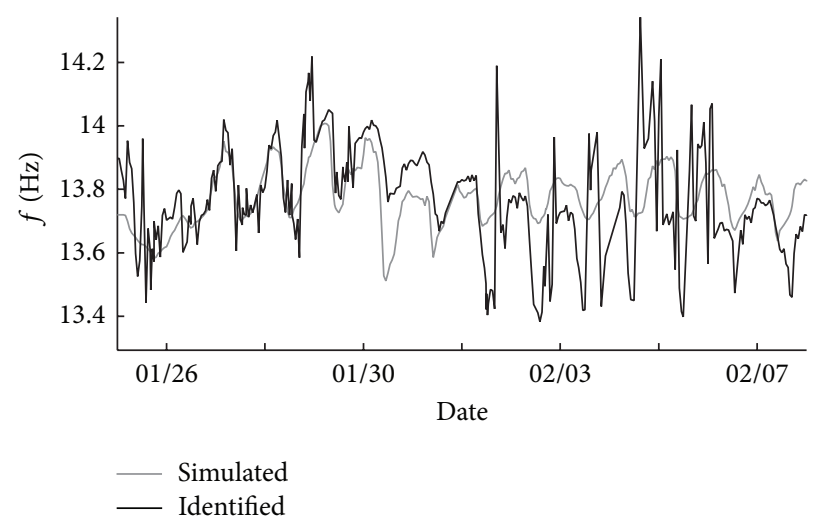

(f)

FIGURE 10: Time-variation of identified and fourth-order model simulated natural frequencies of all six modes [32].

a structure are highly correlated. The correlated features could seriously deteriorate the generalization performance of regression model. Subsequently, the principal component analysis (PCA) was added before conducting SVM algorithm [86]. The PCA is first applied to extract principal components from the measured temperatures for dimensionality reduction. The predominant feature vectors in conjunction with the measured modal frequencies are then fed into an SVM algorithm to formulate regression models that may take into account thermal inertia effect. The proper hyperparameters to formulate SVR models with good generalization performance were chosen. The proposed method was compared with the method directly using measurement data to train SVM models through the use of long-term measurement data. It was shown that PCA-compressed features make the training and validation of SVM models more efficient in both model accuracy and computational costs. When continuously measured data is available, the dynamic SVR model, which is trained using the augmented temperature vector to account for temporal correlation, provides more accurate frequency prediction than the static SVR model without considering temporal correlation.

With one year of measurement data from the instrumented Ting Kau Bridge, a comparative study of evaluating the effectiveness of four statistical regression/learning methods including linear regression, nonlinear regression, neural network, and SVM for modeling the effect of temperature on modal frequencies was conducted by Ko and $\mathrm{Ni}$ [12]. The predicted results are plotted in Figure 11. It was observed that the linear model reproduces the training data well but 


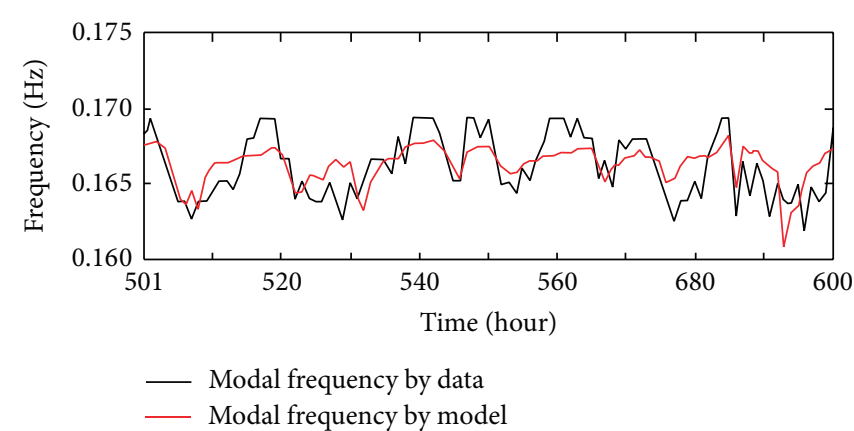

(a) Frequency sequences generated by the linear regression model

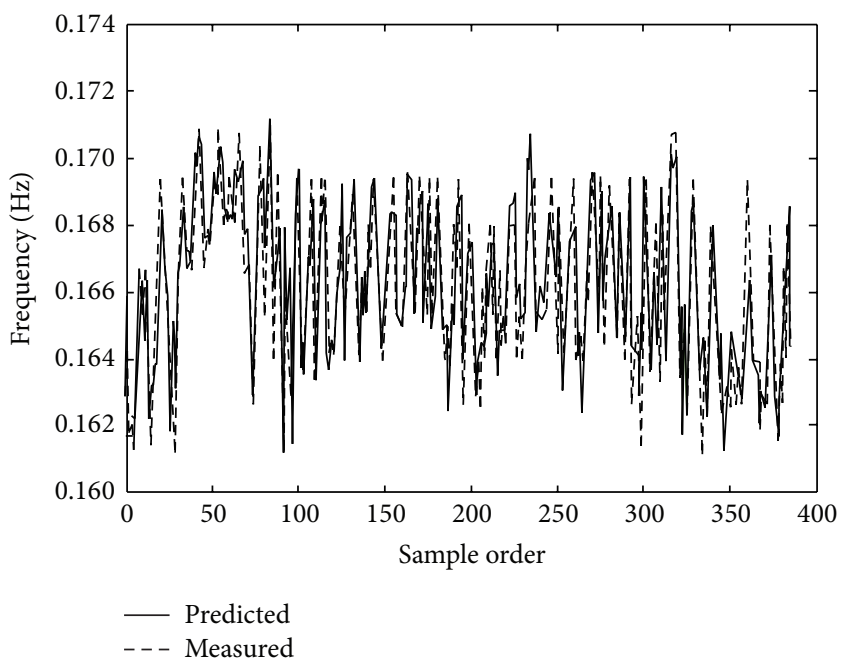

(c) Frequency sequences generated by the neural network model

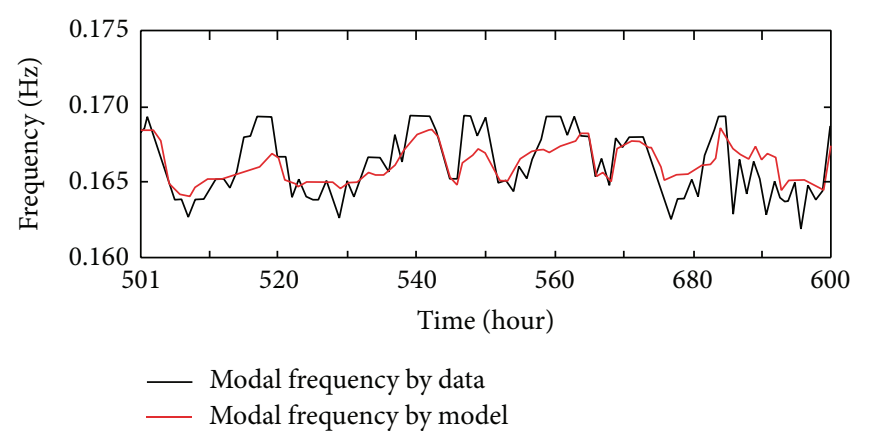

(b) Frequency sequences generated by the nonlinear regression model

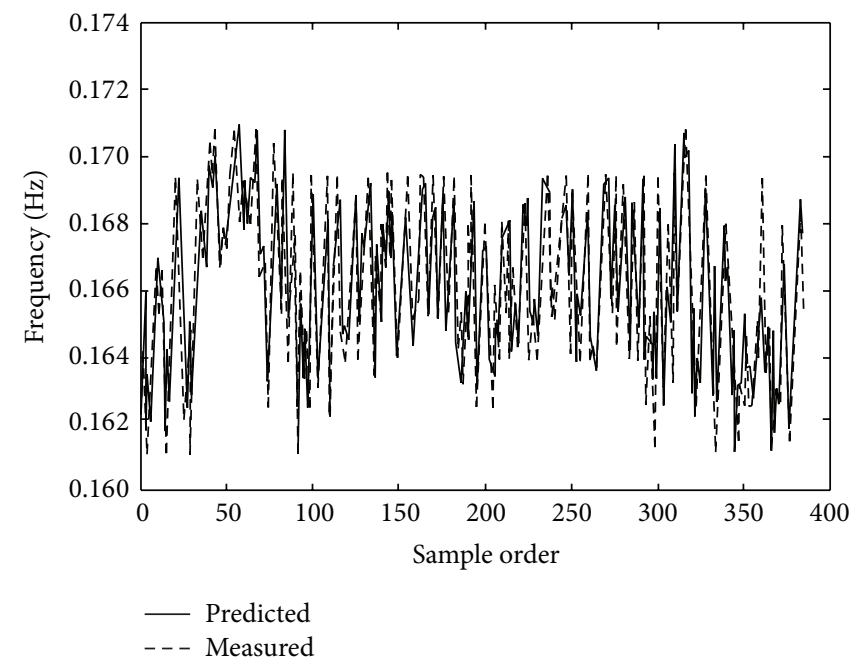

(d) Frequency sequences generated by the support vector machine model

FIGURE 11: The comparison of prediction performance of different models [12].

is poor in predicting fresh validation data. The nonlinear regression model shows stronger generalization capability than the linear model but is still short of accurately predicting the frequency variations. The neural network and SVM models exhibited good capabilities in both reproduction and prediction. It was found that a perception neural network with a single hidden layer is sufficient for modeling the correlation and an appropriate number of hidden nodes is crucial to achieve superior prediction performance of the trained model (excessive hidden nodes may cause serious attenuation of the prediction capability). When an SVM is used for modeling the correlation, the prediction capability of the trained model is heavily dependent on the selection of the SVM coefficients. An advisable way is to determine the model parameters of the SVM model by means of training data while optimizing the SVM coefficients with the use of independent validation data.

Considering that the variations of frequencies of real bridges may be induced by the combined action of temperature and wind, Li et al. [22] investigated the effects of temperature and wind velocity on modal parameters including modal frequencies, modal shapes, and the associated damping ratios of cable-stayed bridges based on nonlinear principal component analysis (NLPCA) and artificial neural network (ANN).
The NLPCA was first employed as a signal preprocessing tool to distinguish temperature and wind effects on structural modal parameters from other environmental factors. Then, the ANN technique was introduced to model the relationship between the preprocessed modal parameters and environmental factors. Sixteen-day continuous measurement of acceleration, temperature, and wind velocity, which was recorded by a sophisticated long-term SHM system, were used in this study. Numerical results indicated that modal parameters preprocessed by NLPCA can retain the most features of original signals. The ANN regression models have good capacities for mapping the relationship of environmental factors and modal frequency. The proposed regression models showed that the preprocessed modal frequency and damping ratios are dramatically affected by temperature. However, temperature effects on the entire modal shapes are insignificant. A similar method was then adopted by Loh and Chen [87].

Ni et al. $[33,88]$ studied the prediction capability of neural network models, established using long-term monitoring data, for correlation between the modal frequencies and environmental temperatures. A total of $770 \mathrm{~h}$ modal frequency and temperature data obtained from an instrumented bridge are available for this study, which are further divided into 


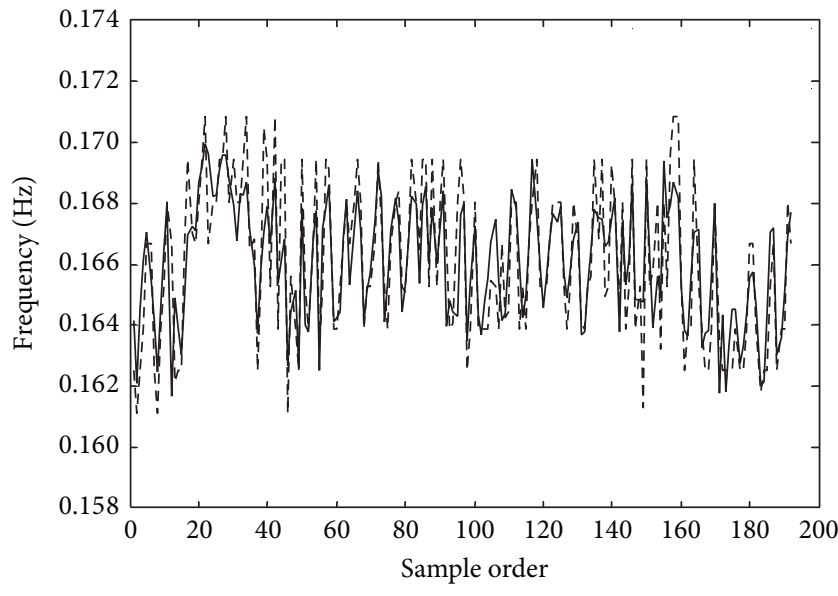

(a) The baseline BPNN model

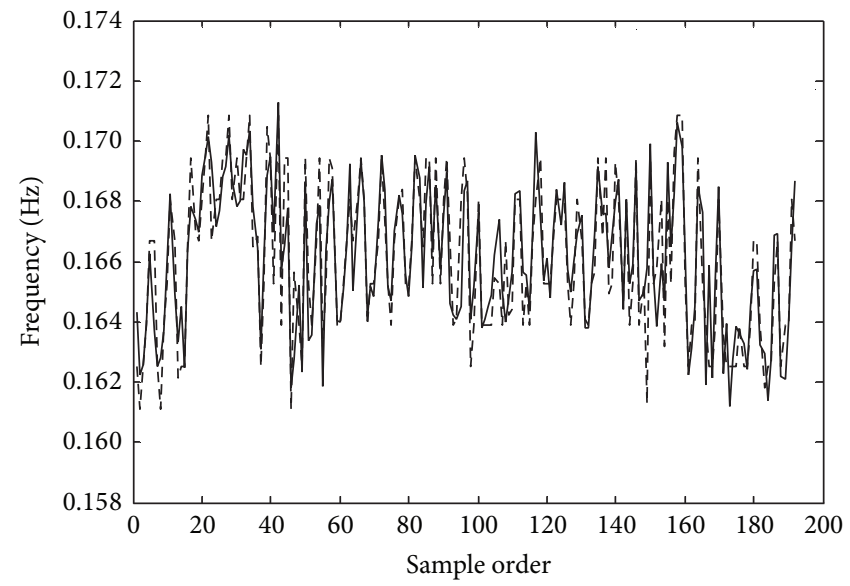

(b) The BPNN model with the early stopping technique

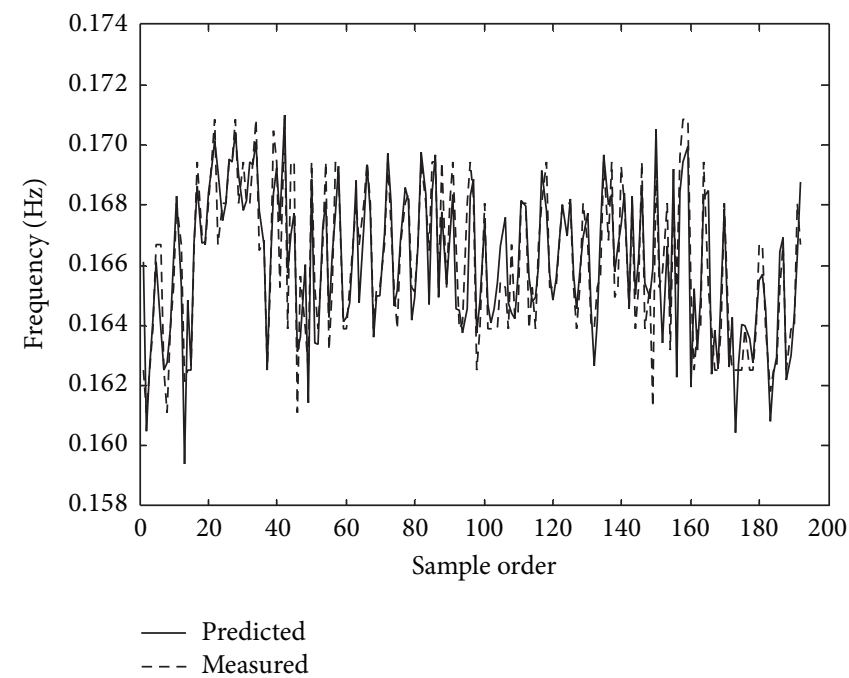

(c) The BPNN model with the Bayesian regularization technique

FIGURE 12: Comparison between BPNN-predicted and measured frequencies for testing data [33].

three sets: training data, validation data, and testing data. Two new back-propagation neural networks (BPNNs) were configured with the same data by applying the early stopping technique and the Bayesian regularization technique, respectively. The reproduction and prediction capabilities of the two new BPNNs were examined with respect to the training data and the unseen testing data and compared with the performance of the baseline BPNN model. The results are shown in Figure 12. It validated that both the early stopping and Bayesian regularization techniques can significantly ameliorate the generalization capability of BPNNbased correlation models, and the BPNN model formulated using the early stopping technique outperforms that using the Bayesian regularization technique in both reproduction and prediction capabilities. Then they addressed the construction of appropriate input to neural networks with intent to enhance the reproduction and prediction capabilities of the formulated correlation models [89]. Making use of the temperature data measured from different portions of the bridge, three kinds of input, that is, mean temperatures, effective temperatures, and principal components (PCs) of temperatures were constructed. It was revealed that the temperature profile characterized by the effective temperatures is insufficient for formulating a good correlation model between the modal frequencies and temperatures. When a sufficient number of PCs are used, the BPNN with input of the PCs of temperatures performs better than the BPNN with input of the mean temperatures in both reproduction and prediction capabilities.

\section{Conclusions and Recommendations}

The variations in vibration properties of long-span bridges are not only caused by structural damage or deterioration but also caused by environmental conditions, especially temperature. Inappropriately estimating the temperature effects on the changes of vibration characteristics of a bridge may 
result in false-positive or false-negative damage detection. To solve this problem, considerable efforts have been devoted to investigating the correlations between temperatures and vibration properties in different types of bridges with the aim of eliminating the temperature effect in vibration-based structural damage detection. However, it is far from sufficient. The temperature distribution in a bridge that is affected by air temperature, wind, humidity, intensity of solar radiation, material type, and so forth changes in a complex way. The more and more complicated configuration of bridges makes the vibration properties multivariate. So at least the following existing problems and promising efforts need particular attention.

(1) The changes of vibration properties in long-span bridges induced by structural damage or temperature are only several percentages. So the extraction of temperaturecaused vibration property variability and damage-caused vibration property variability relies heavily on the accuracy of model parameters. How to identify bridge model parameters, notably mode shape and damping ratio, with a high resolution in noise environment is the fundamental problem of studying the temperature effects on vibration properties of long-span bridges and executing damage detection algorithms. Improving the precision of structural vibration properties identification is a significant work not only for studies of the temperature effect but also for the research of damage detection.

(2) Many new bridges with complicated geometric configuration and novel materials are constructed. The thermal dynamic characteristics such as conduction, emissivity, and absorptivity of those new structures are different from general cases. Besides, modern transport system has extended to extraordinary climate regions. The temperature in those areas is particularly high or particularly low. It was already found that two different relationships between frequencies and temperatures existed below and above freezing. Therefore, studying the correlations between temperatures and vibration properties of various bridges in broad regions is helpful in understanding the activity of temperature on vibration property variations.

(3) Although numerical simulation approach has insufficient accuracy for quantifying the effect of temperature variations on the vibration properties of long-span bridges, it is characterized by high efficiency and easy implementation. This method is an advisable choice when field measurement data are unavailable. The development of the thermodynamics simulation makes the calculation of temperature distribution in bridges by the FE method more reliable. Therefore, studying the correlations between temperatures and vibration properties by the coupled thermomechanics simulation is a promising work.

(4) Successful implementation and operation of longterm SHM systems on bridges have been widely reported, which provide a large number of structural vibration data and corresponding temperature records. But the observation of the correlations between temperatures and vibration properties focuses on only a few bridges. Many measurement results are unused, which induces the potentiality of SHM is considerably reduced. Carrying out an intensive study of temperature influence on bridge vibration properties from SHM data should be encouraged, and particular emphasis should be placed on extracting quantitative models for damage detection.

(5) From field measurement data of acceleration and temperature, many promising models were trained to describe the temperature effects on the variation of vibration properties. However, previous prediction models have been effective when they were used for a specific bridge type. They have not been shown to be applicable to different bridge types. Understanding the potential mechanism of vibration property variability because of the temperature variations can help in developing more rational mathematical relationships between the measured vibration properties and temperatures that are suitable for a wide range of bridge types. In addition, establishing parametric stochastic models are beneficial for predicting temperature-induced variations in the vibration properties of new bridges when temperature data are available.

(6) Advanced statistical methods such as the Bayesian probabilistic framework and the Markov chain Monte Carlo simulation provide effective approaches for establishing statistical models of temperatures and vibration properties. Modern signal processing technologies like the wavelet transform and the Hilbert-Huang transform can extract significant information from complicated and unsystematic measurement data. So developing the correlations between temperatures and vibration properties by advanced statistical methods and modern signal processing technologies may be more robust against uncertainties.

\section{Conflict of Interests}

The authors declare that there is no conflict of interests regarding the publication of this paper.

\section{Acknowledgments}

This research work was jointly supported by the National Natural Science Foundation of China (Grant nos. 51121005, 51308186, and 51222806), the Natural Science Foundation of Jiangsu Province of China (Grant no. BK20130850), and the Research Fund of State Key Laboratory for Disaster Reduction in Civil Engineering (Grant no. SLDRCE12-MB03).

\section{References}

[1] Z. W. Chen, Y. L. Xu, and X. M. Wang, "SHMS-based fatigue reliability analysis of multiloading suspension bridges," Journal of Structural Engineering, vol. 138, no. 3, pp. 299-307, 2011.

[2] Z. W. Chen, Y. L. Xu, Q. Li, and D. J. Wu, "Dynamic stress analysis of long suspension bridges under wind, railway, and highway loadings," Journal of Bridge Engineering, vol. 16, no. 3, pp. 383-391, 2011.

[3] T. H. Yi, H. N. Li, and M. Gu, "Wavelet based multi-step filtering method for bridge health monitoring using GPS and accelerometer," Smart Structures and Systems, vol. 11, no. 4, pp. 331-348, 2013. 
[4] K. Wardhana and F. C. Hadipriono, "Analysis of recent bridge failures in the United States," Journal of Performance of Constructed Facilities, vol. 17, no. 3, pp. 144-150, 2003.

[5] B. F. Spencer Jr. and S. Cho, "Wireless smart sensor technology for monitoring civil infrastructure: technological developments and full-scale applications," in Proceedings of the World Congress on Advances in Structural Engineering and Mechanics (ASEM '11), Seoul, Republic of Korea, 2011.

[6] T. H. Yi, H. N. Li, and M. Gu, "Experimental assessment of high-rate GPS receivers for deformation monitoring of bridge," Measurement, vol. 46, no. 1, pp. 420-432, 2013.

[7] T. Yi, H. Li, and M. Gu, "Full-scale measurements of dynamic response of suspension bridge subjected to environmental loads using GPS technology," Science China Technological Sciences, vol. 53, no. 2, pp. 469-479, 2010.

[8] T. H. Yi, H. N. Li, and M. Gu, "Recent research and applications of GPS based technology for bridge health monitoring," Science China Technological Sciences, vol. 53, no. 10, pp. 2597-2610, 2010.

[9] G. D. Zhou and T. H. Yi, "Recent developments on wireless sensor networks technology for bridge health monitoring," Mathematical Problems in Engineering, vol. 2013, Article ID 947867, 33 pages, 2013.

[10] G. D. Zhou and T. H. Yi, “The nonuniform node configuration of wireless sensor networks for long-span bridge health monitoring," International Journal of Distributed Sensor Networks, vol. 2013, Article ID 797650, 9 pages, 2013.

[11] Y. Q. Ni, X. W. Ye, and J. M. Ko, "Monitoring-based fatigue reliability assessment of steel bridges: analytical model and application," Journal of Structural Engineering, vol. 136, no. 12, pp. 1563-1573, 2010.

[12] J. M. Ko and Y. Q. Ni, "Technology developments in structural health monitoring of large-scale bridges," Engineering Structures, vol. 27, no. 12, pp. 1715-1725, 2005.

[13] Y. Q. Ni, X. W. Ye, and J. M. Ko, "Modeling of stress spectrum using long-term monitoring data and finite mixture distributions," Journal of Engineering Mechanics, vol. 138, no. 2, pp. 175183, 2012.

[14] S. W. Doebling, C. R. Farrar, and M. B. Prime, "A summary review of vibration-based damage identification methods," Shock and Vibration Digest, vol. 30, no. 2, pp. 91-105, 1998.

[15] P. J. S. Cruz and R. Salgado, "Performance of vibration-based damage detection methods in bridges," Computer-Aided Civil and Infrastructure Engineering, vol. 24, no. 1, pp. 62-79, 2009.

[16] G. D. Zhou and T. H. Yi, “The node arrangement methodology of wireless sensor networks for long-span bridge health monitoring," International Journal of Distributed Sensor Networks, vol. 2013, Article ID 865324, 8 pages, 2013.

[17] C. Liu and J. T. DeWolf, "Effect of temperature on modal variability of a curved concrete bridge under ambient loads," Journal of Structural Engineering, vol. 133, no. 12, pp. 1742-1751, 2007.

[18] Y. Zou, L. Tong, and G. P. Steven, "Vibration-based modeldependent damage (delamination) identification and health monitoring for composite structures-a review," Journal of Sound and Vibration, vol. 230, no. 2, pp. 357-378, 2000.

[19] J.-T. Kim, Y.-S. Ryu, H.-M. Cho, and N. Stubbs, "Damage identification in beam-type structures: frequency-based method vs mode-shape-based method," Engineering Structures, vol. 25, no. 1, pp. 57-67, 2003.

[20] A. Alvandi and C. Cremona, "Assessment of vibration-based damage identification techniques," Journal of Sound and Vibration, vol. 292, no. 1-2, pp. 179-202, 2006.
[21] I. Talebinejad, C. Fischer, and F. Ansari, "Numerical evaluation of vibration-based methods for damage assessment of cablestayed bridges," Computer-Aided Civil and Infrastructure Engineering, vol. 26, no. 3, pp. 239-251, 2011.

[22] H. Li, S. Li, J. Ou, and H. Li, "Modal identification of bridges under varying environmental conditions: temperature and wind effects," Structural Control and Health Monitoring, vol. 17, no. 5, pp. 495-512, 2010.

[23] P. Cawley, "Long range inspection of structures using low frequency ultrasound," in Structural Damage Assessment Using Advanced Signal Processing Procedures, University of Sheffield, Sheffield, UK, 1997.

[24] G. D. Zhou and T. H. Yi, "Thermal load in large-scale bridges: a state-of-the-art review," International Journal of Distributed Sensor Networks, vol. 2013, Article ID 217983, 17 pages, 2013.

[25] Y. L. Xu, B. Chen, C. L. Ng, K. Y. Wong, and W. Y. Chan, "Monitoring temperature effect on a long suspension bridge," Structural Control and Health Monitoring, vol. 17, no. 6, pp. 632653, 2010.

[26] A. B. Siddique, B. F. Sparling, and L. D. Wegner, "Assessment of vibration-based damage detection for an integral abutment bridge," Canadian Journal of Civil Engineering, vol. 34, no. 3, pp. 438-452, 2007.

[27] J.-T. Kim, J.-H. Park, and B.-J. Lee, "Vibration-based damage monitoring in model plate-girder bridges under uncertain temperature conditions," Engineering Structures, vol. 29, no. 7, pp. 1354-1365, 2007.

[28] Y. Xia, Y.-L. Xu, Z.-L. Wei, H.-P. Zhu, and X.-Q. Zhou, "Variation of structural vibration characteristics versus nonuniform temperature distribution," Engineering Structures, vol. 33, no. 1, pp. 146-153, 2011.

[29] I. Gonzales, M. Ulker-Kaustell, and R. Karoumi, "Seasonal effects on the stiffness properties of a ballasted railway bridge," Engineering Structures, vol. 57, pp. 63-72, 2013.

[30] Y. Xia, B. Chen, S. Weng, Y. Q. Ni, and Y. L. Xu, “Temperature effect on vibration properties of civil structures: a literature review and case studies," Journal of Civil Structural Health Monitoring, vol. 2, no. 1, pp. 29-46, 2012.

[31] H. Sohn, M. Dzwonczyk, E. G. Straser, A. S. Kiremidjian, K. Law, and T. Meng, "An experimental study of temperature effect on modal parameters of the Alamosa Canyon Bridge," Earthquake Engineering and Structural Dynamics, vol. 28, no. 7-8, pp. 879-897, 1999.

[32] P. Moser and B. Moaveni, "Environmental effects on the identified natural frequencies of the Dowling Hall Footbridge," Mechanical Systems and Signal Processing, vol. 25, no. 7, pp. 2336-2357, 2011.

[33] Y. Q. Ni, H. F. Zhou, and J. M. Ko, "Generalization capability of neural network models for temperature- frequency correlation using monitoring data," Journal of Structural Engineering, vol. 135, no. 10, pp. 1290-1300, 2009.

[34] Y. Xia, H. Hao, G. Zanardo, and A. Deeks, "Long term vibration monitoring of an RC slab: temperature and humidity effect," Engineering Structures, vol. 28, no. 3, pp. 441-452, 2006.

[35] R. W. Clough and J. Penzien, Dynamics of Structure, McGrawHill, New York, NY, USA, 2nd edition, 1993.

[36] Y. Fu and J. T. DeWolf, "Monitoring and analysis of a bridge with partially restrained bearings," Journal of Bridge Engineering, vol. 6, no. 1, pp. 23-29, 2001.

[37] J. H. G. Macdonald and W. E. Daniell, "Variation of modal parameters of a cable-stayed bridge identified from ambient 
vibration measurements and FE modelling," Engineering Structures, vol. 27, no. 13, pp. 1916-1930, 2005.

[38] Z.-D. Xu and Z. Wu, "Simulation of the effect of temperature variation on damage detection in a long-span cable-stayed bridge," Structural Health Monitoring, vol. 6, no. 3, pp. 177-189, 2007.

[39] É. Balmès, M. Basseville, L. Mevel, and H. Nasser, "Handling the temperature effect in vibration monitoring of civil structures: a combined subspace-based and nuisance rejection approach," Control Engineering Practice, vol. 17, no. 1, pp. 80-87, 2009.

[40] C. Miao, L. Chen, and Z. Feng, "Study on effects of environmental temperature on dynamic characteristics of Taizhou Yangtze River Bridge," Engineering Science, vol. 9, no. 2, pp. 79-84, 2011.

[41] É. Balmès, M. Basseville, F. Bourquin, L. Mevel, H. Nasser, and F. Treyssède, "Merging sensor data from multiple temperature scenarios for vibration monitoring of civil structures," Structural Health Monitoring, vol. 7, no. 2, pp. 129-142, 2008.

[42] L. M. Sun and Z. H. Min, "Evaluations on dynamic behaviors and its environmental influence factors of bridge based on long term monitoring," in Proceedings of the 4th International Symposium on Lifetime Engineering of Civil Infrastructure, Changsha, China, 2009.

[43] L. Sun, Y. Zhou, and X. Li, "Correlation study on modal frequency and temperature effects of a cable-stayed bridge model," Advanced Materials Research, vol. 446-449, pp. 32643272, 2012.

[44] Y. Xia, B. Chen, X.-Q. Zhou, and Y.-L. Xu, "Field monitoring and numerical analysis of Tsing Ma Suspension Bridge temperature behavior," Structural Control and Health Monitoring, vol. 20, no. 4, pp. 560-575, 2013.

[45] J. D. Turner, An experimental and theoretical study of dynamic methods of bridge conditioning monitoring [Ph.D. thesis], University of Reading, Berkshire, UK, 1984.

[46] J. D. Turner and A. J. Pretlove, "A study of the spectrum of traffic-induced bridge vibration," Journal of Sound and Vibration, vol. 122, no. 1, pp. 31-42, 1988.

[47] V. Askegaard and P. Mossing, "Long term observation of RCbridge using changes in natural frequency," Nordic Concrete Research, no. 7, pp. 20-27, 1988.

[48] M. G. Wood, Damage analysis of bridge structures using vibrational techniques [Ph.D. thesis], Aston University, 1992.

[49] R. G. Rohrmann and W. F. Rucker, "Surveillance of structural properties of large bridges using dynamic methods," in Proceedings of 6th International Conference on Structural Safety and Reliability, pp. 977-980, 1994.

[50] W. F. Rucker, S. Said, R. G. Rohrmann, and W. Schmid, "Load and condition monitoring of a highway bridge in a continuous manner," in Proceedings of the IABSE Symposium on Extending the Lifespan of Structures, vol. 73, San Francisco, Calif, USA, 1995.

[51] J. T. DeWolf, P. E. Conn, and P. N. O’leary, “Continuous monitoring of bridge structures," in Proceedings of the International Association for Bridge and Structural Engineering Symposium (IABSE '95), pp. 934-940, 1995.

[52] J. Zhao and J. T. Dewolf, "Dynamic monitoring of steel girder highway bridge," Journal of Bridge Engineering, vol. 7, no. 6, pp. 350-356, 2002.

[53] C. R. Farrar, S. W. Doebling, P. J. Cornwell, and E. G. Straser, "Variability of modal parameters measured on the Alamosa Canyon Bridge," in Proceedings of the 15th International Modal Analysis Conference (IMAC'97), pp. 257-263, February 1997.
[54] S. W. Doebling and C. R. Farrar, "Using statistical analysis to enhance modal-based damage identification," in Proceedings of the Structural Damage Assessment Using Advanced Signal Processing Procedures, pp. 199-210, 1997.

[55] P. Cornwell, C. R. Farrar, S. W. Doebling, and H. Sohn, "Environmental variability of modal properties," Experimental Techniques, vol. 23, no. 6, pp. 45-48, 1999.

[56] C. R. Farrar and D. A. Jauregui, "Comparative study of damage identification algorithms applied to a bridge: I. Experiment," Smart Materials and Structures, vol. 7, no. 5, pp. 704-719, 1998.

[57] M. A. Wahab and G. De Roeck, "Effect of temperature on dynamic system parameters of a highway bridge," Structural Engineering International, vol. 7, no. 4, pp. 266-270, 1997.

[58] G. P. Roberts and A. J. Pearson, "Health monitoring of structures-towards a stethoscope for bridges," in Proceedings of the International Seminar on Modal Analysis, vol. 2, pp. 947-952, 1999.

[59] S. Alampalli, "Influence of in-service environment on modal parameters," in Proceedings of the 16th International Modal Analysis Conference (IMAC '98), pp. 111-116, February 1998.

[60] R. G. Rohrmann, M. Baessler, S. Said, W. Schmid, and W. F. Ruecker, "Structural causes of temperature affected modal data of civil structures obtained by long time monitoring," in Society of Photo-Optical Instrumentation Engineers, SPIE Proceedings Series, pp. 1-7, February 2000.

[61] J. Maeck, B. Peeters, and G. De Roeck, "Damage identification on the Z24-bridge using vibration monitoring analysis," in Proceedings of European COST F3 Conference on System Identification and Structural Health Monitoring, pp. 233-242, 2000.

[62] B. Peeters and G. De Roeck, "One-year monitoring of the Z24Bridge: environmental effects versus damage events," Earthquake Engineering \& Structural Dynamics, vol. 30, no. 2, pp. 149171, 2001.

[63] B. Peeters, J. Maeck, and G. De Roeck, "Vibration-based damage detection in civil engineering: excitation sources and temperature effects," Smart Materials and Structures, vol. 10, no. 3, pp. 518-527, 2001.

[64] Y. Q. Ni, X. G. Hua, K. Q. Fan, and J. M. Ko, "Correlating modal properties with temperature using long-term monitoring data and support vector machine technique," Engineering Structures, vol. 27, no. 12, pp. 1762-1773, 2005.

[65] S. L. Desjardins, N. A. Londoño, D. T. Lau, and H. Khoo, "Realtime data processing, analysis and visualization for structural monitoring of the confederation bridge," Advances in Structural Engineering, vol. 9, no. 1, pp. 141-157, 2006.

[66] C. Liu and J. T. DeWolf, "Effect of temperature on modal variability for a curved concrete bridge," in Smart Structures and Materials 2006: Sensors and Smart Structures Technologies for Civil, Mechanical, and Aerospace Systems, vol. 6174 of Proceedings of SPIE, March 2006.

[67] J.-T. Kim, W.-B. Na, J.-H. Park, and J.-S. Lee, "Structural health monitoring and risk alarming in plate-girder bridges under uncertain temperature condition," in Smart Structures and Materials 2005: Sensors and Smart Structures Technologies for Civil, Mechanical, and Aerospace Systems, vol. 5765 of Proceedings of SPIE, pp. 1002-1011, San Diego, Calif, USA, March 2005.

[68] Y. L. Ding and A. Q. Li, “Temperature-induced variations of measured modal frequencies of steel box girder for a long-span suspension bridge," International Journal of Steel Structures, vol. 11, no. 2, pp. 145-155, 2011. 
[69] Y. L. Ding, A. Q. Li, and F. F. Geng, "Variability of measured modal frequencies of a suspension bridge under actual environmental effects," in Proceedings of the 5th International Conference on Bridge Maintenance, Safety and Management (IABMAS '10), pp. 1392-1398, Lehigh University, July 2010.

[70] A. A. Mosavi, R. Seracino, and S. Rizkalla, "Effect of temperature on daily modal variability of a steel-concrete composite bridge," Journal of Bridge Engineering, vol. 17, no. 6, pp. 979-983, 2012.

[71] G. M. Lloyd, M. L. Wang, and V. Singh, "Observed variations of mode frequencies of a prestressed concrete bridge with temperature," in Proceedings of the 14th Engineering Mechanics Conference, pp. 179-189, American Society of Civil Engineers, May 2000.

[72] G. M. Lloyd, M. L. Wang, and V. Singh, "Observed variations of mode frequencies of a prestressed concrete bridge with temperature," in Condition Monitoring of Materials and Structures, pp. 179-189, 2000.

[73] J. Kullaa, "Eliminating environmental influences in structural health monitoring using spatiotemporal correlation models," in Proceedings of the 1st European Workshop on Structural Health Monitoring, pp. 742-749, 2002.

[74] M. Breccolotti, G. Franceschini, and A. L. Materazzi, "Sensitivity of dynamic methods for damage detection in structural concrete bridges," Shock and Vibration, vol. 11, no. 3-4, pp. 383394, 2004.

[75] W. Song and S. J. Dyke, "Ambient vibration based modal identification of the Emerson bridge considering temperature effects," in Proceedings of the 4th World Conference on Structural Control and Monitoring, pp. 11-13, 2006.

[76] Z. J. Yang, U. Dutta, D. Zhu, E. Marx, and N. Biswas, "Seasonal frost effects on the soil-foundation-structure interaction system," Journal of Cold Regions Engineering, vol. 21, no. 4, pp. 108-120, 2007.

[77] S. K. Di, L. X. Wang, H. Li, and Z. S. Wu, "Stochastic subspace identification research of concrete girders considering temperature influence," in Proceedings of the 4th International Symposium on Environment Vibrations-Prediction, Monitoring, Mitigation and Evaluation, Beijing, China, 2009.

[78] V. Zabel, M. Brehm, and S. Nikulla, "The influence of temperature varying material parameters on the dynamic behavior of short span railway bridges," in Proceedings of the 24th International Conference on Noise and Vibration Engineering, Leuven, Belgium, 2010.

[79] L. Wang, J. L. Hou, and J. P. Ou, “Temperature effect on modal frequencies for a rigid continuous bridge based on long term monitoring," in Conference on Nondestructive Characterization for Composite Materials, Aerospace Engineering, Civil Infrastructure, and Homeland, Proceedings of SPIE, 2011.

[80] A. Cury, C. Cremona, and J. Dumoulin, "Long-term monitoring of a PSC box girder bridge: operational modal analysis, data normalization and structural modification assessment," Mechanical Systems and Signal Processing, vol. 33, pp. 13-37, 2012.

[81] K. Y. Koo, J. M. W. Brownjohn, D. I. List, and R. Cole, “Structural health monitoring of the Tamar suspension bridge," Structural Control and Health Monitoring, vol. 20, no. 4, pp. 609-625, 2013.

[82] H. Sohn, M. Dzwonczyk, E. G. Straser, K. H. Law, T. Meng, and A. S. Kiremidjian, "Adaptive modeling of environmental effects in modal parameters for damage detection in civil structures," in Proceedings of the 5th Annual International Symposium on Smart Structures and Materials, pp. 127-138, International Society for Optics and Photonics, March 1998.
[83] H. Sohn, "Effects of environmental and operational variability on structural health monitoring," Philosophical Transactions of the Royal Society A, vol. 365, no. 1851, pp. 539-560, 2007.

[84] C. Liu, J. T. DeWolf, and J.-H. Kim, "Development of a baseline for structural health monitoring for a curved post-tensioned concrete box-girder bridge," Engineering Structures, vol. 31, no. 12, pp. 3107-3115, 2009.

[85] B. Moaveni and I. Behmanesh, "Effects of changing ambient temperature on finite element model updating of the Dowling Hall Footbridge," Engineering Structures, vol. 43, pp. 58-68, 2012.

[86] X. G. Hua, Y. Q. Ni, J. M. Ko, and K. Y. Wong, "Modeling of temperature-frequency correlation using combined principal component analysis and support vector regression technique," Journal of Computing in Civil Engineering, vol. 21, no. 2, pp. 122135, 2007.

[87] C. H. Loh and M. C. Chen, "Modeling of environmental effects for vibration-based shm using recursive stochastic subspace identification analysis," in Proceedings of the 4th Asia-Pacific Workshop on Structural Health Monitoring, Melbourne, Australia, 2013.

[88] H. F. Zhou, Y. Q. Ni, and J. M. Ko, "Eliminating temperature effect in vibration-based structural damage detection," Journal of Engineering Mechanics, vol. 137, no. 12, pp. 785-796, 2012.

[89] H. F. Zhou, Y. Q. Ni, and J. M. Ko, "Constructing input to neural networks for modeling temperature-caused modal variability: mean temperatures, effective temperatures, and principal components of temperatures," Engineering Structures, vol. 32, no. 6, pp. 1747-1759, 2010. 


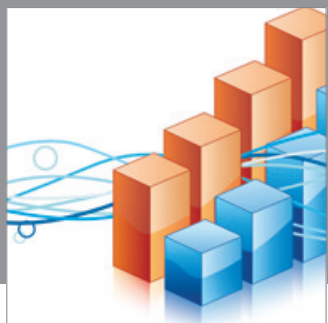

Advances in

Operations Research

mansans

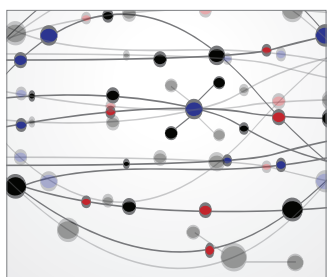

The Scientific World Journal
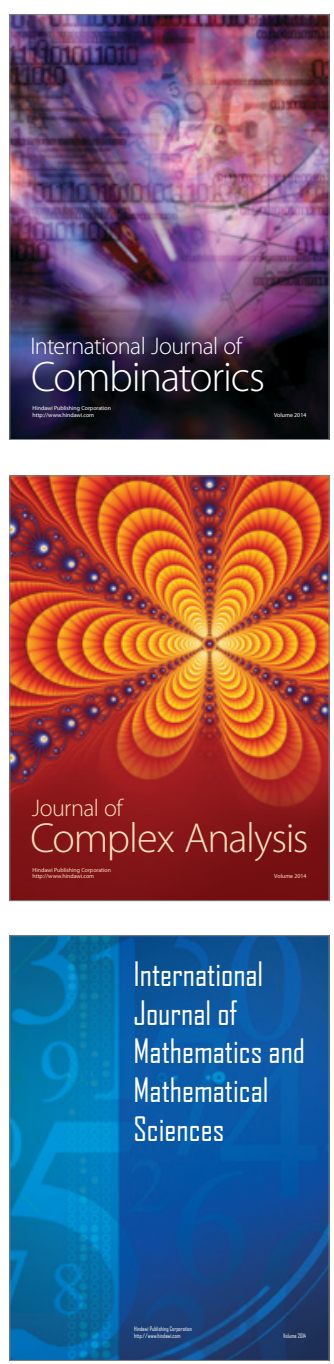
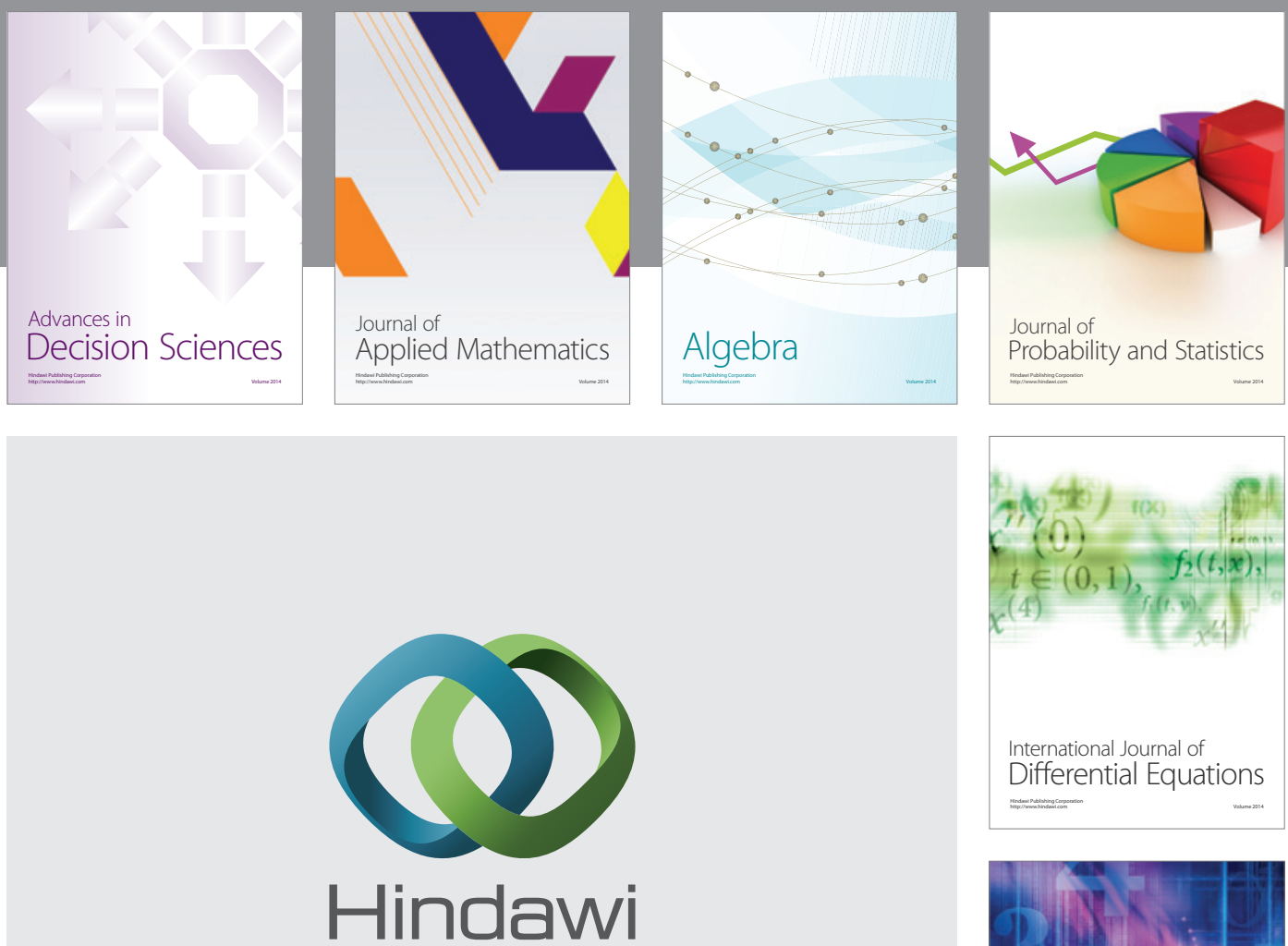

Submit your manuscripts at http://www.hindawi.com
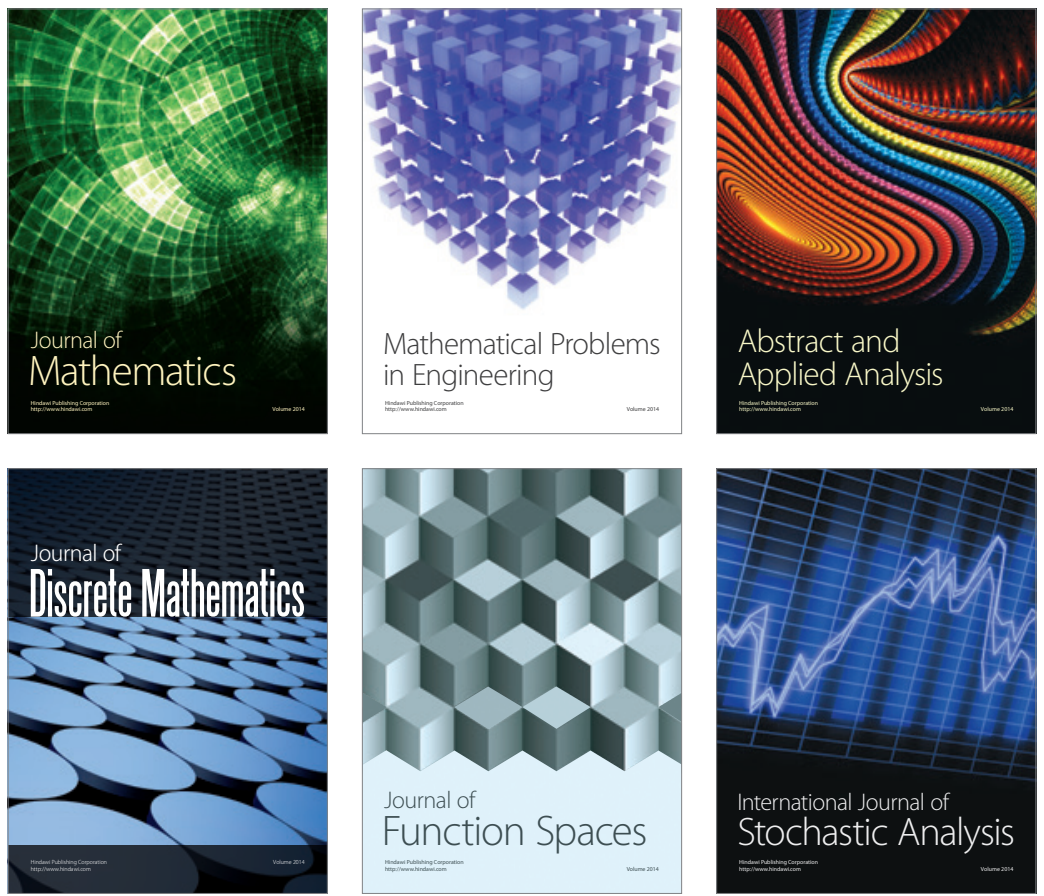

Journal of

Function Spaces

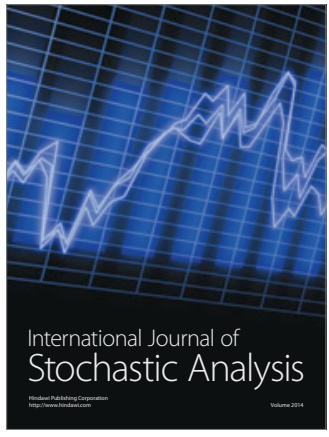

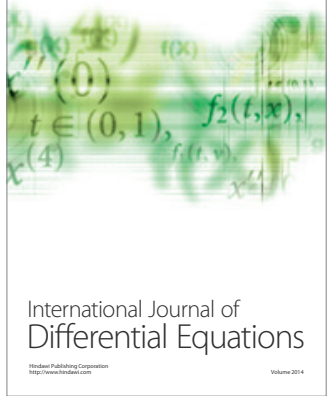
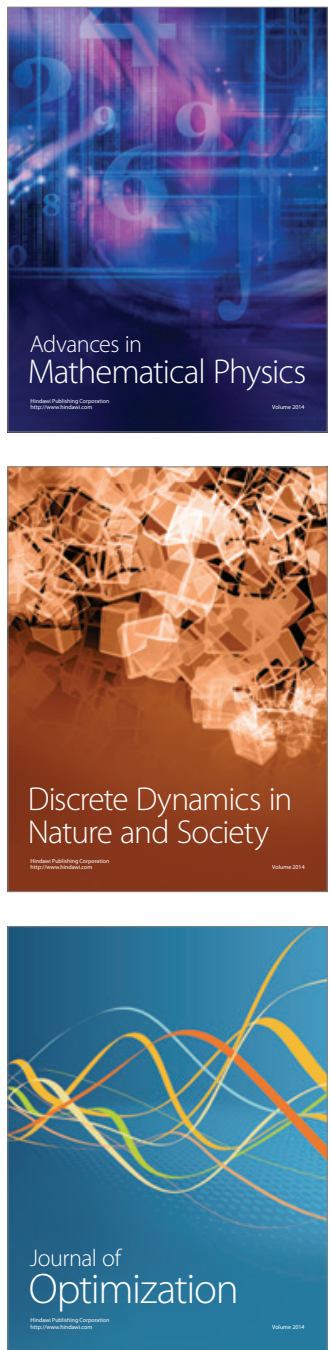